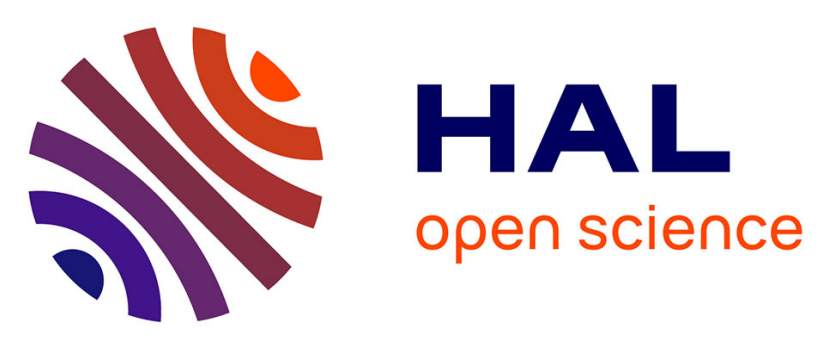

\title{
A new route for manufacturing poly(aminophosphonic)-functionalized poly(glycidyl methacrylate)-magnetic nanocomposite - Application to uranium sorption from ore leachate
}

Ahmed Galhoum, Wael Eisa, Ibrahim El-Tantawy El-Sayed, Ahmad Tolba, Zeinab Shalaby, Said Mohamady, Sally Muhammad, Shimaa Hussien, Takaya Akashi, Eric Guibal

\section{- To cite this version:}

Ahmed Galhoum, Wael Eisa, Ibrahim El-Tantawy El-Sayed, Ahmad Tolba, Zeinab Shalaby, et al.. A new route for manufacturing poly(aminophosphonic)-functionalized poly(glycidyl methacrylate)magnetic nanocomposite - Application to uranium sorption from ore leachate. Environmental Pollution, 2020, 264, pp.114797. 10.1016/j.envpol.2020.114797 . hal-02613916

\section{HAL Id: hal-02613916 https://hal.mines-ales.fr/hal-02613916}

Submitted on 20 Nov 2020

HAL is a multi-disciplinary open access archive for the deposit and dissemination of scientific research documents, whether they are published or not. The documents may come from teaching and research institutions in France or abroad, or from public or private research centers.
L'archive ouverte pluridisciplinaire $\mathbf{H A L}$, est destinée au dépôt et à la diffusion de documents scientifiques de niveau recherche, publiés ou non, émanant des établissements d'enseignement et de recherche français ou étrangers, des laboratoires publics ou privés. 


\title{
A new route for manufacturing poly(aminophosphonic)- functionalized poly(glycidyl methacrylate)-magnetic nanocomposite - Application to uranium sorption from ore leachate
}

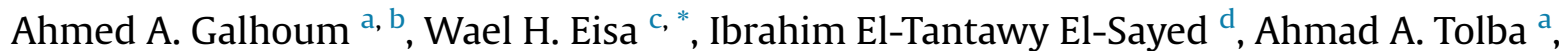 \\ Zeinab M. Shalaby ${ }^{a}$, Said I. Mohamady ${ }^{\text {a }}$, Sally S. Muhammad ${ }^{a}$, Shimaa S. Hussien ${ }^{\text {a }}$, \\ Takaya Akashi ${ }^{\mathrm{b}}$, Eric Guibal ${ }^{\mathrm{e}}$ \\ a Nuclear Materials Authority, P.O. Box 530, El-Maadi, Cairo, Egypt \\ ${ }^{\mathrm{b}}$ Faculty of Bioscience and Applied Chemistry, Hosei University, 3-7-2, Kajino-chou, Koganei, Tokyo, 184-8584, Japan \\ ' Spectroscopy Department, Physics Division, National Research Centre (NRC), Egypt \\ ${ }^{\mathrm{d}}$ Chemistry Department, Faculty of Science, Menoufia University, Shebin El-Kom, Egypt \\ e Institut Mines Telecom - Mines Ales, Polymer Composites and Hybrids, PCH, 6 avenue de Clavières, F-30319, Alès cedex, France
}

\section{A B S T R A C T}

A high-energy ball milling of magnetite nanoparticles with amino-phosphonic functionalized poly(glycidyl methacrylate) polymer is used for manufacturing a highly efficient magnetic sorbent for $\mathrm{U}(\mathrm{VI})$ sorption from aqueous solutions. The Uranyl ions were adsorbed through the binding with amine and phosphonic groups as confirmed by Fourier Transform infrared (FTIR) and X-ray photoelectron spectroscopy (XPS) analyses. The maximum sorption capacity (up to $270 \mathrm{mg} \mathrm{U} \mathrm{g}^{-1}$ ) occurred at $\mathrm{pH}=3-4$; Langmuir isotherm well describes the sorption process. Small-size particles allow achieving fast uptake (within $\approx 90$ min of contact); and the kinetic profiles are modeled by the pseudo-second order rate equation. Uranium is successfully desorbed from loaded sorbent using $0.25 \mathrm{M} \mathrm{NaHCO}_{3}$ solution: Sorbent can be recycled with minimal decrease in sorption and desorption efficiency for at least 6 cycles. The sorbent is efficiently used for $\mathrm{U}(\mathrm{VI})$ recovery from the acidic leachates of U-bearing ores (after precipitation pre-treatment). Sorption capacity approaches $190 \mathrm{mg} \mathrm{U} \mathrm{g}^{-1}$ despite the presence of high concentrations of $\mathrm{Fe}$ and $\mathrm{Si}$ : the sorbent has a marked preference for $\mathrm{U}(\mathrm{VI})$ (confirmed by distribution ratios and selectivity coefficients).

Keywords:

Magnetic functionalized

poly(glycidylmethacrylate)

Aminophosphonic groups

Uranyl recovery

Sorption isotherms

Uptake kinetics

\section{Introduction}

The proper toxicity of uranium but also the importance of securing the resource, both in terms of availability (expected shortage) and national/regional independence explain that the removal and recovery of the metal from low-concentration effluents is a strategic issue for nuclear energy industry (Crawford et al., 2017; Imam et al., 2018; Xie et al., 2019; Yuan et al., 2011). Many different techniques have been developed for uranium recovery depending on the concentration range, the complexity of the solutions, the water volumes to be treated. Precipitation is appropriate for the treatment of large flow rates with low metal

\footnotetext{
* Corresponding author. El buhouth st., Dokki, Cairo, 12622. Egypt. E-mail address: waeleisa@yahoo.com (W.H. Eisa).
}

concentrations (Biswas et al., 2015; Burns et al., 2016), precipitation may be assisted by pre-reduction of the metal, including bioreduction process (Zhang et al., 2013). These techniques are usually poorly selective and the precipitates are difficult to valorize. Solvent extraction is highly efficient for concentrated solutions (Zhu et al., 2016). For more dilute solutions, these processes are not competitive. The impregnation of solid porous supports with extractant offers interesting alternative to solvent extraction (Huang et al., 2017; Rahmani-Sani et al., 2015; Zayed et al., 2015). Indeed, the process allows maintaining the high efficiency and selectivity of solvent extraction while confining the solvent phase into the porosity of the support and preventing its loss and dispersion in the aqueous phase.

However, a wide range of sorbents and biosorbents has been investigated for the last decades for uranium recovery from dilute solutions. Resins offer many possibilities by grafting different 
functional groups at the surface of macroporous or gel-like polymers (Amphlett et al., 2018a; Amphlett et al., 2018b; Ang et al., 2018; Dlamini et al., 2019; Duval et al., 2019; Kong et al., 2018; Liu et al., 2017; Liu et al., 2018; Negm et al., 2019; Rodas Ceballos et al., 2019; Solgy et al., 2015). This versatility in the functional groups helps in designing materials with higher selectivity for target metals.

Alternatively, inorganic materials have been also investigated, including clays (Gladysz-Plaska et al., 2018; Olivelli et al., 2013) metal oxides (Yin et al., 2017), mesoporous silica under their raw form (Guibal et al., 1995), chemically modified (El-Magied et al., 2018; Mazario et al., 2019; Yin et al., 2015; Yuan et al., 2011), or functionalized by chemical anchoring (Awual, 2019). Composite materials, including, metal-organic frameworks have also been designed for metal binding. Carbon-based materials have also retained a great attention due to their highly porous structures and their easily chemical modification (Lu et al., 2017; Song et al., 2019; Wang et al., 2012; Yu et al., 2019; Zhang et al., 2016).

Biopolymers have also widely investigated using for example raw, and functionalized chitosan (Elwakeel et al., 2014; Imam et al., 2018; Mahfouz et al., 2015; Mincke et al., 2019).

More recently, a photocatalytic reaction revealed great potential for the sorption of uranyl ions from aqueous solutions (Liang et al., 2020). A magnetic support $\left(\mathrm{ZnFe}_{2} \mathrm{O}_{4}\right)$ was developed, for converting $\mathrm{U}(\mathrm{VI})$ into $\mathrm{U}(\mathrm{IV})$ under visible-light irradiation. The material shows outstanding efficiency for $\mathrm{U}(\mathrm{VI})$ removal, especially when the material is synthesized as nanorods.

Frequently the main limiting steps associated with sorption processes deal with resistance to mass transfer. The challenge consists of improving the porosity or using small-size materials, at the expense of more complex solid/liquid separation at the end of the sorption. This drawback can be ruled out using magnetic-based composites. This is the strategy followed in the present work for designing a new sorbent for uranium recovery.

\section{Rationale for the design of the PPA-PGMA/Fe ${ }_{3} \mathrm{O}_{4}$ sorbent (by solid-state manufacturing)}

Glycidyl methacrylate (GMA) bears vinyl and epoxy reactive functionalities. These reactive groups open the way for chemical functionalization by ring-opening reaction with a wide range of reagents including amines, carboxylic acids, etc. (Galhoum et al., 2019; Sun et al., 2013). The easiness of its functionalization and polymerization/cross-linking (to form poly(glycidyl methacrylate), PGMA), its abundance and cost-effectiveness may explain this monomer has been considered an important resource for preparing new sorbents. The choice of functionalization agent is usually driven by the affinity of reactive groups for target metals according the Hard and Soft Acid Base theory (HSAB) (Cao et al., 2013; Galhoum et al., 2019; Ren et al., 2016). Uranium (present as uranyl ions $\left(\mathrm{UO}_{2}^{2+}\right)$ ) behaves as a hard acid showing great reactivity toward hard bases. Hence, chelating agents, having functional groups of $\mathrm{P}$, $\mathrm{N}$, and $\mathrm{O}$, exhibit higher efficiency toward selective sorption of uranium (i.e. high sorption capacity with selective separation properties). Especially, organophosphorous compounds have been widely used for the separation and purification of uranium (Cao et al., 2013; Imam et al., 2018; Ren et al., 2016; Yuan et al., 2011).

Global sorption properties are not only controlled by the proper reactivity of functional groups but also by the mass transfer properties of the resins: textural properties (including porosity and specific surface area) control the accessibility to internal reactive groups. Improving these criteria may consist in decreasing the size of sorbent particles to decrease the intraparticle diffusion path. The main drawback at using micro or nano-objects consists of the management of separation and confinement properties. This drawback can be overcome using magnetic micro/nano-particles (Kharissova et al., 2015; Philippova et al., 2011), or magnetic nanofibers (Jiang et al., 2015). Fig. S1 (and relevant descriptions) reports different strategies for synthesizing nanocomposite magnetic particles. This is usually achieved using a procedure consisting of the hydrothermal simultaneous polymerization (or coprecipitation) of the coating polymer and synthesis of magnetite core. For instance, the magnetic $\mathrm{Fe}_{3} \mathrm{O}_{4}$ inside chitosan was prepared via one-step hydrothermal reaction (Mahfouz et al., 2015). On the other hand, Sun et al. used an in situ approach to prepare polymer/ $\mathrm{Fe}_{3} \mathrm{O}_{4}$ core/shell structure (Sun et al., 2013). Magneticnanocomposite core-shell structures were synthesized by encapsulation of homogeneously dispersed magnetic $\left(\mathrm{Fe}_{3} \mathrm{O}_{4}\right)$ nanoparticles within the structure of polymer matrix (Fig. S1, See AMS) (Kharissova et al., 2015; Philippova et al., 2011). These synthetic routes are hampered with critical environmental issues, complicated preparation steps, and low yield-production, which may significantly reduce the feasibility or interest of the process. Recently, the solid-state manufacturing emerges as an alternative and facile approach for the preparation of core-shell nanocomposites. The solid-state methods are characterized by simple processing and handling, low pollution, cost-effective and availability for large-scale production (Chini et al., 1990; Eisa and Shabaka, 2013). The in situ generation (or co-generation) of magnetic nanoparticles with the polymerization or precipitation of polymer/biopolymer network makes difficult the optimization of the synthesis of the two components (because of the necessity to comply with common experimental conditions).

In addition, the solid-state process allows overcoming some drawbacks associated to prolonged storage of magnetic nanoparticles: the aggregation and agglomeration of nanoparticles, which, in turn, may cause significant decrease in sorption properties.

A solid-state method was developed to prepare PPA-PGMA/ $\mathrm{Fe}_{3} \mathrm{O}_{4}$ nanocomposites using planetary ball milling technique. PGMA was first functionalized with amino and aminoalkyl phosphonic groups (Scheme 1). Thereafter, the functionalized polymer was milled with preformed $\mathrm{Fe}_{3} \mathrm{O}_{4}$ nanoparticles to prepare PPAPGMA/Fe3O4 core-shell sorbent. Elemental analysis, X-ray diffraction (XRD), Fourier Transform Infrared (FTIR), X-ray photoelectron spectroscopy (XPS), Transmission electron microscope (TEM), zeropoint charge (pHpzc), thermal gravimetric analysis (TGA), BET surface area, and vibrating-sample magnetometer (VSM). The sorption properties for $\mathrm{U}(\mathrm{VI})$ recovery are investigated by studying the $\mathrm{pH}$ value effect, uptake kinetics, sorption isotherms, thermodynamic parameters. Metal desorption and sorbent recycling are evaluated over five cycles. Finally, the sorbent is tested for uranium recovery from acidic leachates of local ore.

\section{Experimental}

\subsection{Materials}

$\mathrm{FeSO}_{4}, \mathrm{FeCl}_{3}$, Glycidyl methacrylate (GMA), formaldehyde (37\%), diethylenetriamine (DETA), ethanol (99.5\%), poly(vinylpyrrolidone) (PVP K-30), and 2,2-azobisisobutyronitrile (AIBN) were obtained from Wako Chemical Co. Ltd. Phosphorous acid $\left(\mathrm{H}_{3} \mathrm{PO}_{4}\right)$ was obtained from Sigma-Aldrich Co. Different solutions of uranium were prepared by diluting the pre-prepared stock solution of $\left(1 \mathrm{~g} \mathrm{U} \mathrm{L}^{-1}\right)$ $\mathrm{UO}_{2}\left(\mathrm{OCOCH}_{3}\right)_{2} \cdot 2 \mathrm{H}_{2} \mathrm{O}$ in $\mathrm{H}_{2} \mathrm{SO}_{4}$. Arsenazo III (A.R grade) was obtained from Fluka AG (Buchs, Switzerland). The concentrations of uranium before and after sorption treatments were measured using Arsenazo III (Fluka AG) colorimetric method (Marczenko, 1986). All other chemicals were obtained from Prolabo (VWR-France, Fontenay sous Bois, France), and were used as received. 


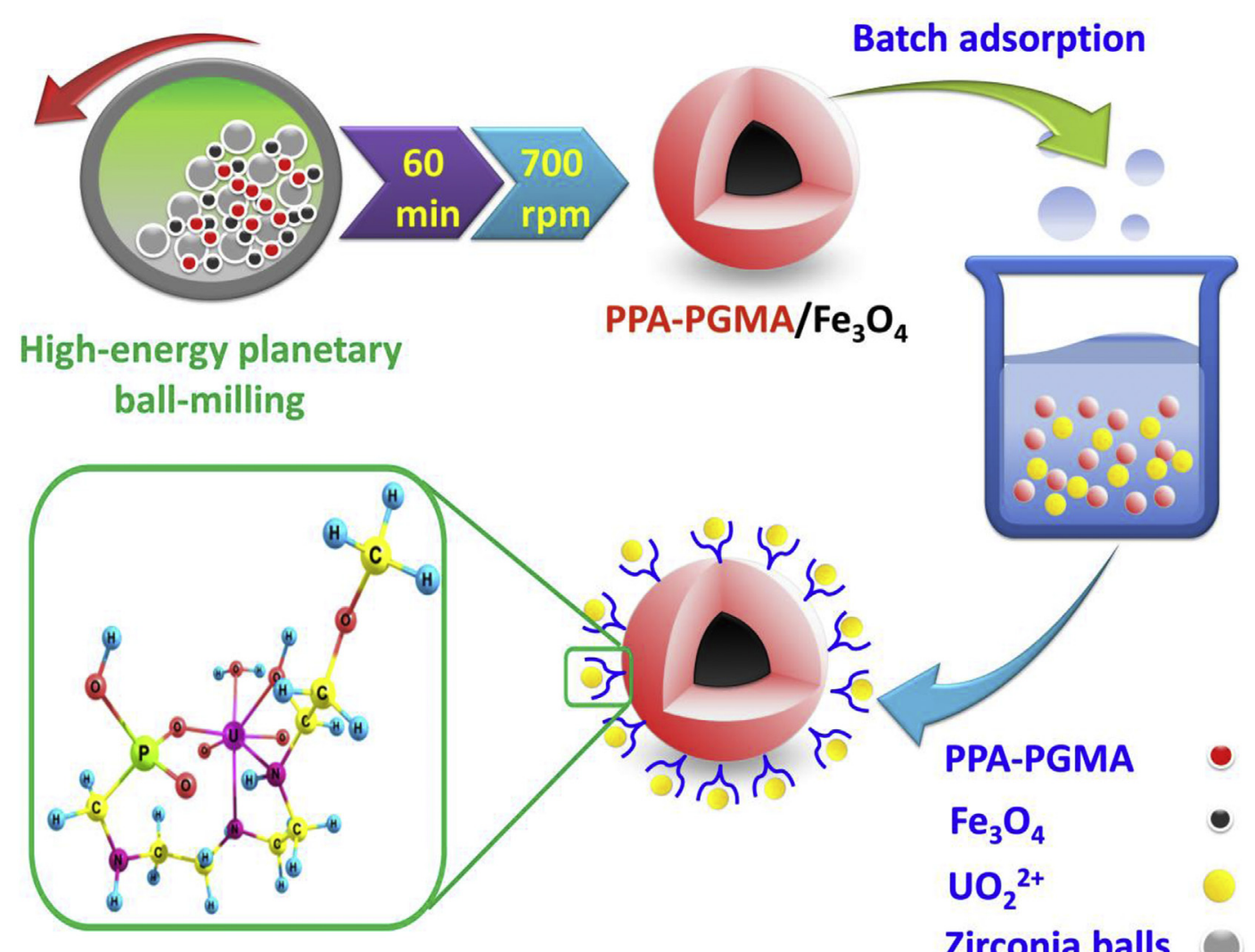

Scheme 1. The uranium sorption by solid-state-synthesized PPA-PGMA/ $/ \mathrm{Fe}_{3} \mathrm{O}_{4}$ nanocomposite.

\subsection{Preparation of sorbent}

\subsubsection{Preparation of magnetite nanoparticles}

Magnetite particles were produced by the hydrothermal precipitation of two precursors $\left(\mathrm{FeSO}_{4}\right.$ and $\mathrm{FeCl}_{3}$ ) (Mahfouz et al., 2015). The bi-component solution (with a 1:2 M ratio $\mathrm{Fe}(\mathrm{II}) /$ $\mathrm{Fe}(\mathrm{III})$ ) was mixed at $40{ }^{\circ} \mathrm{C}$ while adding progressively $\mathrm{NaOH}(2 \mathrm{M})$ to adjust $\mathrm{pH}$ to $10-10.5$, under $\mathrm{N}_{2}$ atmosphere. The mixture was then heated, under agitation, at $80{ }^{\circ} \mathrm{C}$ for $60 \mathrm{~min}$. The precipitate was collected by magnetic separation (using supermagnets). Deaerated water (under $\mathrm{N}_{2}$ flow) was used for rinsing the precipitate, which was finally dried at room temperature.

\subsubsection{Synthesis of functionalized PGMA (polyglycidyl methacrylate): PPA-PGMA}

Scheme 2 shows the sequential stages for the functionalization of PGMA with poly(phosphonic amine) (PPA-PGMA). The detailed synthesis of PPA-PGMA was previously reported (Galhoum et al., 2019). Briefly, dispersion polymerization route was used to produce PGMA microspheres as follow: $3 \mathrm{~g}$ of PVP were dissolved in $90 \mathrm{~mL}$ ethanol/water solution (90/10) in a $250 \mathrm{~mL}$ four-necked flask. $10 \mathrm{~g}$ of the monomer GMA were loaded with $0.2 \mathrm{~g}$ of AIBN (polymerization initiator) and then transferred into the PVP solution. The mixture was subjected to $\mathrm{N}_{2}$ gas bubbling for $30 \mathrm{~min}$ to get rid of dissolved oxygen. Thereafter, the reaction was mechanically stirred and refluxed at $70{ }^{\circ} \mathrm{C}$ for $24 \mathrm{~h}$ (Galhoum et al., 2019; Sun et al., 2013). Microspheres (product (i), PGMA) were collected by centrifugation, washed repeatedly with DI-water and ethanol, and vacuum-dried at ambient temperature. In the next step, $10 \mathrm{~g}$ of PGMA were dispersed in $20 \mathrm{~mL}$ ethanol followed by addition of $12 \mathrm{~mL}$ DETA. The reaction refluxed and stirred for $18 \mathrm{~h}$ (Galhoum et al., 2019; Mahfouz et al., 2015). The aminated product (ii) (TAPGMA) was washed and collected by filtration. Finally, $1 \mathrm{~g}$ of (ii) was added to the $100 \mathrm{~mL}$ solution of phosphorous acid $\left(5 \mathrm{~g} / 100 \mathrm{~mL} \mathrm{H}_{2} \mathrm{O}\right.$ / $\mathrm{HCl}(1 / 1 \mathrm{v} / \mathrm{v}))$ and refluxed in a $200-\mathrm{mL}$ three-necked flask. The formaldehyde solution $(20 \mathrm{~mL})$ was dropwisely added for $1 \mathrm{~h}$ and the reaction proceeded under reflux for $24 \mathrm{~h}$ (Galhoum et al., 2019). The end product PPA-PGMA was collected via filtration, repeatedly washed with ethanol and water, and dried at $70{ }^{\circ} \mathrm{C}$ for $24 \mathrm{~h}$.

\subsubsection{Synthesis of PPA-PGMA/Fe $\mathrm{O}_{3}$ core-shell nanocomposite}

$0.5 \mathrm{~g}$ of $\mathrm{Fe}_{3} \mathrm{O}_{4}$ powder and $1 \mathrm{~g}$ of PPA-PGMA were milled within YTZ jar using $15 \mathrm{~g}$ of YTZ balls $\left(\mathrm{Y}_{2} \mathrm{O}_{3}-\mathrm{ZrO}_{2}\right.$ : 95\% $\mathrm{ZrO}_{2} / 5.6 \% \mathrm{Y}_{2} \mathrm{O}_{3}$; diameter: $2 \mathrm{~mm}$ ). The milling process was carried out using highenergy planetary ball-milling (Fritsch Planetary Mills Pulverisette 7 classic line, Idar-Oberstein, Germany) at $700 \mathrm{rpm} / 60 \mathrm{~min}$ (including 1-min stop every $20 \mathrm{~min}$ ). The use of high-energy ball milling is attributed to its ease of operation and efficiency in mixing and dispersing the inorganic and organic materials homogeneously as well as it is available for mass production of nanomaterials at room temperature (Han et al., 2016). Inorganic and organic fractions were intimately and homogeneously distributed; the dispersion of prepared material in water, under vigorous agitation, showed the stability of the composite material.

\subsection{Characterization of sorbent}

The crystalline phase was determined using X-ray diffractometer (XRD) of the type (RIGAKU SmartLab, Tokyo, Japan), with $\mathrm{Cu} \mathrm{K}_{\alpha}$ radiation source. Thermogravimetric analyzer of the type (EXSTAR 6000 TG/DTA 6300N, Seiko Instruments Inc. (SII), Tokyo, Japan) TG/ DTA analyses was used to follow the thermal degradation behavior. 
(A)<smiles>C=C(C)C(=O)OCC1CO1</smiles><smiles></smiles><smiles>CCCCCC(COC(=O)C(C)(C)C(C)(C)C)NCCNCCN</smiles><smiles>CCCCCCC(=O)C(C)(C)C(C)(C)COC(=O)C(C)(C)CN(CCN(CCN(CP(=O)(O)O)CP(=O)(O)O)CP(=O)(O)O)C(CO)CP(=O)(O)O</smiles>

(B)

Pathway A: $\mathrm{S}_{\mathrm{N}}{ }^{1}$

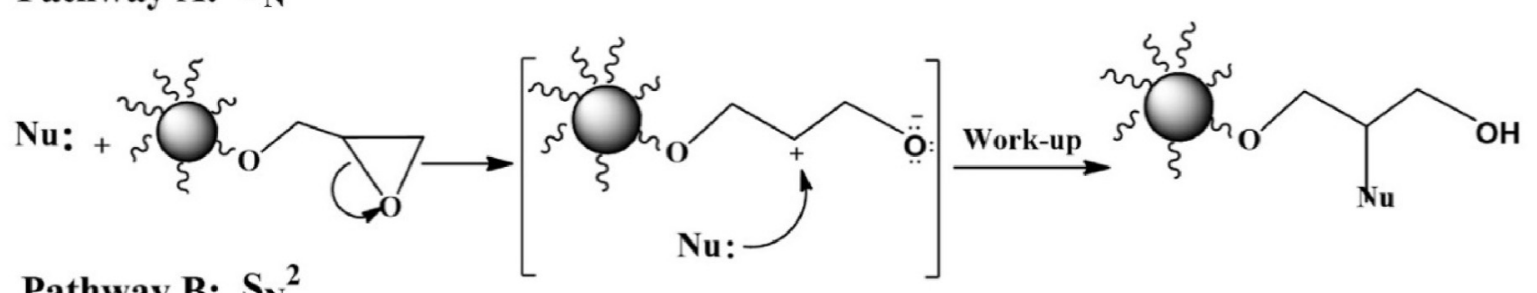

Pathway B: $\mathrm{S}_{\mathrm{N}}{ }^{2}$

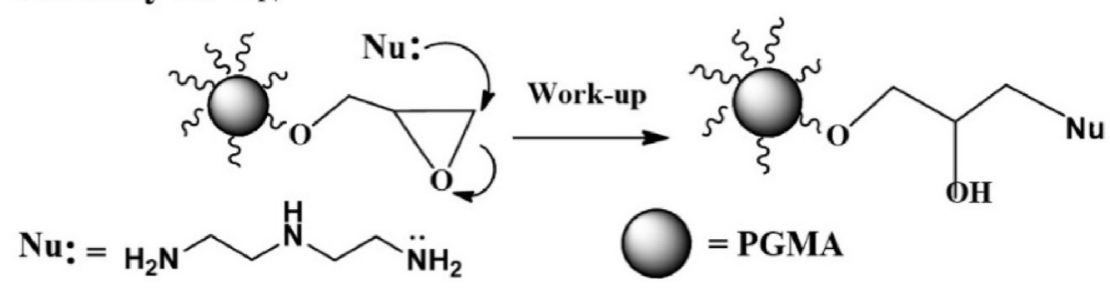

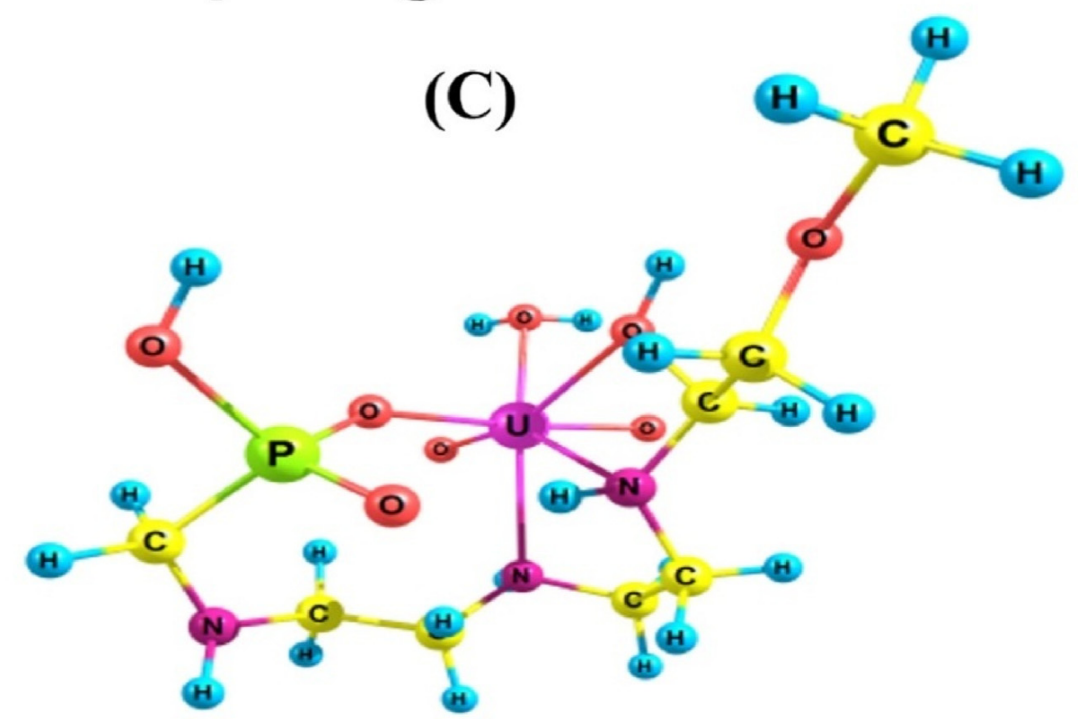

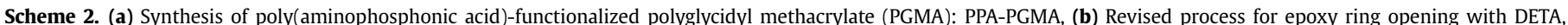

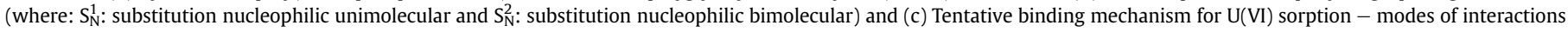
between reactive groups on PPA-PGMA/ $/ \mathrm{Fe}_{3} \mathrm{O}_{4}$ and uranyl complexes. 
Dynamic light scattering (DLS) (Zetasizer Nano ZS, Malvern Instruments Ltd., UK) was used to determine the size distribution of the nanocomposite. Evaluation of the magnetic properties was assessed using a vibrating-sample magnetometer (VSM) (730T, Lakeshoper, America). Quantachrome Nova 3200 surface analyzer (Boynton Beach, FL, USA) was used to analyze the textural properties of PPA-PGMA/ $\mathrm{Fe}_{3} \mathrm{O}_{4}: \mathrm{N}_{2}$ adsorption-desorption isotherms where acquired after degassing the samples at $30^{\circ} \mathrm{C}$, while the pore volume was measured according to the BJH method.

The elemental analysis was assessed using Micro Corder JM10 analyzer (J-Science Lab Co., Ltd., Japan). The FT-IR spectra were collected using FT/IR-6600 spectrometer (Jasco, Japan) for the analysis of PGMA, PPA-PGMA and PPA-PGMA/Fe $3 \mathrm{O}_{4}$. For the comparison of FTIR spectra for sorbent before and after uranyl sorption (and after 5 cycles of sorption and desorption) analyses were carried out on a Nicolet IS10 FTIR spectrometer (Thermo Fisher Scientific, Waltham, MA, USA). The X-ray photoelectron spectroscopy (XPS) was carried out using Perkin Elmer PHI 5600 ESCA spectrometer (USA). The high resolution-transmission electron microscopy (HR-TEM JEOL-2100, Jeol, Japan) was used to study the shape and size of the nanocomposite samples. The $\mathrm{pH}_{\mathrm{PZC}}$ value of the samples (the $\mathrm{pH}$ related to the zero-charge of the sorbent surface) was evaluated according to the pH-drift method (Lopez-Ramon et al., 1999). A series of $0.1 \mathrm{M} \mathrm{NaCl}$ (at different $\mathrm{pH}$ value) was used in equilibration of the sorbent under agitation for $24 \mathrm{~h}$. The $\mathrm{pH}$ at equilibrium $\left(\mathrm{pH}_{\mathrm{eq}}\right.$ ) was determined and the $\mathrm{pH}_{\mathrm{PzC}}$ is the $\mathrm{pH}$ value related to $\mathrm{pH}_{\mathrm{i}}=\mathrm{pH}_{\mathrm{eq}}$. The concentration of uranium was measured using UV/Vis spectrophotometer (SP-8001 Metertech Inc, Taiwan).

\subsection{Uranium sorption from synthetic solutions}

The sorption properties were studied in terms of $\mathrm{pH}$ effect, uptake kinetics, sorption isotherms, temperature effect, metal desorption, and sorbent recycling. Batch experiment was performed by adding $0.02 \mathrm{~g}$ of the sorbent to $40 \mathrm{~mL}$ of aqueous ura-

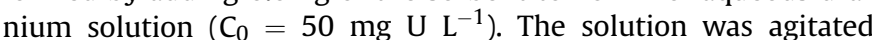
$(200 \mathrm{rpm})$ for $12 \mathrm{~h}$ at room temperature. The sorbent particles were filtrated on cellulose acetate membrane filter and high-power magnetic separation. Thereafter, Arsenazo III colorimetry method was used to determine the concentration of residual uranium in the solution $\left(\mathrm{C}_{\mathrm{eq}}, \mathrm{mg} \mathrm{U} \mathrm{L}^{-1}\right)$. The uranium concentration in the sorbent ( $\mathrm{q}_{\mathrm{eq}}, \mathrm{mg} \mathrm{U} \mathrm{g}^{-1}$ ) was determined by the mass balance equation: $\mathrm{q}_{\mathrm{eq}}=\left(\mathrm{C}_{0}-\mathrm{C}_{\mathrm{eq}}\right) \times \mathrm{V} / \mathrm{m}$, where $\mathrm{C}_{0}$ and $\mathrm{C}_{\mathrm{eq}},\left(\mathrm{mg} \mathrm{U} \mathrm{L}^{-1}\right)$, are the initial and final $\mathrm{U}(\mathrm{VI})$ concentration, respectively. The distribution ratio $\mathrm{D}$ $\left(\mathrm{L} \mathrm{g}^{-1}\right)$ is calculated by the $\mathrm{q}_{\mathrm{eq}} / \mathrm{C}_{\mathrm{eq}}$ ratio. The study of $\mathrm{pH}$ effect was carried out using $50 \mathrm{mg} \mathrm{U} \mathrm{L}^{-1}$ solutions at initial $\mathrm{pH}$ varied from 1 to 6 . The $\mathrm{pH}$ was not adjusted during the sorption process the equilibrium $\mathrm{pH}$ was monitored $\left(\mathrm{pH}_{\mathrm{eq}}\right)$. The sorbent dosage (SD) was kept at $0.5 \mathrm{~g} \mathrm{~L}^{-1}$. For uptake kinetics, $\mathrm{C}_{0}=100 \mathrm{mg} \mathrm{U} \mathrm{L}^{-1}(\mathrm{pH}=4$, $\mathrm{SD}=0.5 \mathrm{~g} \mathrm{~L}^{-1}$ ). The collection of samples occurred at constant time intervals and the concentration of residual metal was determined after solid/liquid separation. The experimental conditions for the sorption isotherms were initial $\mathrm{pH}=4.0$, uranyl concentrations varied from 25 to $400 \mathrm{mg} \mathrm{U} \mathrm{L}^{-1}$, and the SD was kept unchanged at $0.5 \mathrm{~g} \mathrm{~L}^{-1}$. Residual concentrations after $4 \mathrm{~h}$ of agitation were determined to calculate sorption capacities. The experiments were duplicated/triplicated and the standard deviation was less than $6 \%$.

\subsection{The reusability test}

The sorption and desorption efficiencies of $\mathrm{U}(\mathrm{VI})$ were determined for five successive sorption-desorption runs using the same sorbent. The sorption experiment was carried out through adding the sorbent $(20 \mathrm{mg})$ to $\mathrm{U}(\mathrm{VI})$ solution $\left(40 \mathrm{~mL}, \mathrm{C}_{0}: 250 \mathrm{mg} \mathrm{U} \mathrm{L}^{-1}\right)$ for $3 \mathrm{~h}$ at room temperature. Thereafter, metal analysis and mass balance calculation were performed. The sorbent was rinsed with demineralized water, after the sorption step, before being processed to desorb metal. The desorption of $\mathrm{U}(\mathrm{VI})$ was carried out at room temperature by mixing the collected sorbent with $\mathrm{NaHCO}_{3}$ solution $(5 \mathrm{~mL}, 0.25 \mathrm{M})$. The contact time was set at $1.5 \mathrm{~h}$ (under constant agitation) between the eluent and the metal-loaded sorbent. The concentration of uranium in the eluate was determined after phase separation and the desorption efficiency was calculated using mass balance equation. The sorption and desorption efficiencies were evaluated at each step (together with the sorption capacity and the eluate concentration). The desorption efficiency $(D E)$ was calculated by: $\mathrm{DE}=\mathrm{C}_{\mathrm{D}} \times \mathrm{V}_{(\mathrm{L})} \times 100 / \mathrm{q}_{\mathrm{d}} \times \mathrm{m}_{\mathrm{d}}$ ) where $\mathrm{q}_{\mathrm{d}}$ $\left(\mathrm{mg} \mathrm{g}^{-1}\right)$ is the sorption capacity for metal loaded material (before desorption), $C_{D}\left(\mathrm{mg} \mathrm{L}^{-1}\right)$ the metal concentration in the eluate, $V_{\mathrm{L}}$ (L) the volume of eluent, and $\mathrm{m}_{\mathrm{D}}(\mathrm{g})$ the amount of sorbent used for desorption step.

Table S1 reports the main equations used for modeling uptake kinetics and sorption isotherms. Non-linear regression analysis (using Mathematica ${ }^{\circledR}$ software, Wolfram-France, Paris, France) was used for the determination of model parameters.

\subsection{Leaching of uranium ore and sorption}

The mining area of El-Sella is located in the Southern Eastern desert of Egypt (Latitudes: $22^{\circ} 14^{\prime} 30^{\prime \prime}-22^{\circ} 18^{\prime} 36^{\prime \prime}$ N/Longitudes: $\left.36^{\circ} 11^{\prime} 45^{\prime \prime}-36^{\circ} 16^{\prime} 30^{\prime \prime} \mathrm{E}\right)$. This place is located about $60 \mathrm{~km}$ far at the south west of the City of Abu Ramad (Red Sea Governorate). The mineral background of this area is mainly constituted of potash feldspar, plagioclase, muscovite and biotite. Other secondary minerals such as sericite, kaolinite and chlorite are also identified. The mining deposit of G. El-Sella contains uranium as a secondary minerals (mainly constituted of uranophane, $\mathrm{Ca}\left(\mathrm{UO}_{2}\right)_{2}\left(\mathrm{SiO}_{3} \mathrm{OH}\right)_{2} .5$ $\mathrm{H}_{2} \mathrm{O}$ )): uranium is already present under its oxidized form; this is especially important for acidic leaching since the addition of oxidizing agent is not necessary for improving metal recovery. Acidic agitation leaching was operated for selective uranium release. Ore was grinded and the fraction corresponding to the particle size below 100 mesh (i.e., inferior to $149 \mu \mathrm{m}$ ) was collected. Ore leaching was performed under agitation for $6 \mathrm{~h}$ using $50 \mathrm{~g} \mathrm{~L}^{-1}$ $\mathrm{H}_{2} \mathrm{SO}_{4}$ solution, at $50{ }^{\circ} \mathrm{C}$; solid/liquid ratio was set to $1: 3$ (100 g of ore for $300 \mathrm{~mL}$ of sulfuric acid). Ore slurry was filtered and the residue was thoroughly washed with demineralized water. The leachate and residue washes were mixed and adjusted to $300 \mathrm{ml}$ with demineralized water to produce the pregnant leach solution (PLS), which was analyzed for $\mathrm{U}$ and base metal contents. The $\mathrm{pH}$ of the acid leachate was close to 2.03. The PLS was pre-treated by $\mathrm{pH}$ control, using $\mathrm{NaOH}$, up to $\mathrm{pH}$ 3.5-4 (precipitated PLS, PPLS) for reduction of iron content and optimization of $\mathrm{pH}$ for $\mathrm{U}(\mathrm{VI})$ recovery.

The treatment of PPLS was operated in batch reactor under experimental conditions comparable to those used for synthetic solutions (i.e., $\mathrm{pH}_{0}$ : 4; $\mathrm{SD}$ : $0.5 \mathrm{~g} \mathrm{~L}^{-1}$; time: $180 \mathrm{~min}$; room temperature (i.e., $25 \pm 1^{\circ} \mathrm{C}$ ); and agitation speed: $200 \mathrm{rpm}$ ).

Metal concentration in the leachate was determined by titration for $U$ to avoid the interference commonly observed with the spectrophotometric method (Davies and Gray, 1964) (Mathew et al., 2009). More specifically, uranium analysis was performed using the oxidimetric titration method against ammonium metavanadate using diphenylamine sulfonate as an indicator. Ammonium ferros was used to reduce uranium just prior analysis (Davies and Gray, 1964). Rapid silicate method was employed to quantify the major oxides in the ore (Shapiro, 1975): Alkaline solution was used to dissolve the ore for $\mathrm{SiO}_{2}$ determination whereas the ore was dissolved in acidic solution for the determination of $\mathrm{MgO}, \mathrm{TiO}_{2}$, $\mathrm{CaO}, \mathrm{Al}_{2} \mathrm{O}_{3}, \mathrm{P}_{2} \mathrm{O}_{5}, \mathrm{Fe}_{2} \mathrm{O}_{3}$ oxides (etc.). $\mathrm{Si}, \mathrm{Al}$, and $\mathrm{P}$ elements were determined by spectrophotometry $(\mathrm{Si}, \mathrm{Al}, \mathrm{P}), \mathrm{Ca}$ and $\mathrm{Fe}$ were 
determined by titration ( $\mathrm{Ca}, \mathrm{Fe}$ ), and $\mathrm{Ti}, \mathrm{Mn}, \mathrm{Mg}, \mathrm{Na}$, and $\mathrm{K}$ were determined by atomic absorption (AAS). or atomic absorption spectrometry (AAS) (Ti, Mn, Mg, Na, K) (Shapiro, 1975). The AAS analyses were performed using a Solar Unicam 969 AAS (Thermo Scientific, Waltham, MA, USA).

\section{Results and discussion}

\subsection{Sorbent characterization}

Scheme 2 displays the synthesis steps of PPA-PGMA. The dispersion polymerization method was used to prepare PGMA (micro-particles $>75 \mu \mathrm{m}$ ). The PGMA is functionalized with $-\mathrm{NH}_{2}$ groups via epoxide ring opening and reaction with DETA. Detailed mechanisms are discussed in Annex A of Supplementary Information.

scheme $2 \mathrm{~b}$ shows two pathways $\left(\mathrm{A}\left(\mathrm{S}_{\mathrm{N}}^{1}\right)\right.$ or $\left.\mathrm{B}\left(\mathrm{S}_{\mathrm{N}}^{2}\right)\right)$ which could be involved in the nucleophilic attack of nitrogen (present in terminal $-\mathrm{NH}_{2}$ ) by the three membered epoxy ring. Pathway A suggests that the opening of the epoxy ring is regioselective (at the internal carbon atom), produce more stable internal secondary carbonium ion. For pathway B, primary less stable carbonium ion is obtained in case of nitrogen atom attacking occurs at the external carbon (less sterically hindered). Regarding to the above scenarios, pathway A is more favored for the synthesis of polyaminated molecule (DETAPGMA) (Chini et al., 1990; Durán Pachón et al., 2003).

Finally, the phosphonic acid groups react with amine functions in the presence of formaldehyde to produce methylene phosphonic groups grafted onto the intermediate product. There are different types of derivatives that could be produced due to the insertion of methylene phosphonic functionalities onto chitosan (using $\mathrm{H}_{3} \mathrm{PO}_{3}$ and formaldehyde). These derivatives may have one or two phosphonomethyl moiety for poly-substituted structure i.e. the structure of grafted polymer may contain both mono-, and disubstituted amine (e.g. Polymer $-\mathrm{NH}-\mathrm{CH}_{2}-\mathrm{PO}_{3} \mathrm{H}_{2}$ and/or Polymer $-\mathrm{N}\left(-\mathrm{CH}_{2}-\mathrm{PO}_{3} \mathrm{H}_{2}\right)_{2}$ ) (Elsalamouny et al., 2017; Ramos et al., 2003).

\subsubsection{Physical characterization}

4.1.1.1. Nano-structure characterization - transmission electron microscopy. Differential light scattering analysis shows that the average size of the magnetic core-shell nanocomposite is $828 \pm 67 \mathrm{~nm}$ (Fig. S2). The global structure is constituted of nanoparticle assemblies. Nanocomposite morphological features were characterized by TEM (Fig. 1 and Fig. S3). Nanoparticles are roughly spherical and homogeneously distributed; they can be described as monodisperse. However, iron oxide nanoparticles (i.e., $\mathrm{Fe}_{3} \mathrm{O}_{4}$ ) tend to aggregate, probably due to dipole/dipole magnetic attraction (Mahfouz et al., 2015). The size of $\mathrm{Fe}_{3} \mathrm{O}_{4}$ particles remains below $20 \mathrm{~nm}$; this confirms the sorbent can be considered a nanocomposite (Kharissova et al., 2015). The particles (average diameter 40-50 nm) show color gradient area: the dark color is due to the crystalline $\mathrm{Fe}_{3} \mathrm{O}_{4}$ fraction of the composite. This dense fraction (core) is embedded into bright areas (shell) which are related to the polymer chains. This color gradient is attributed to the difference in the electron-absorbing abilities (i.e. electron absorbing ability of $\mathrm{Fe}_{3} \mathrm{O}_{4}$ is higher than that of polymer shell) (Hasanpour et al., 2012). HRTEM images clearly show the appearance of lattice fringes with spacing close to $2.47( \pm 0.11) \AA$ (Fig. 1c). Lu et al. reported a lattice fringe close to $2.5 \AA$ for superparamagnetic $\mathrm{Fe}_{3} \mathrm{O}_{4}$ nanoparticles (Lu et al., 2010); this spacing is usually associated with the (311) lattice plane of the cubic $\mathrm{Fe}_{3} \mathrm{O}_{4}$ form. The SAED illustrates the polycrystalline nature of the composite (Fig. 1d) i.e. sharp and continuous rings are observed. The high purity of the nanocomposites is confirmed by the absence of parasite signals associated with contaminants. The diffraction pattern is consistent with XRD analysis (see next section) with identification of the planes associated with spinel structure of cubic $\mathrm{Fe}_{3} \mathrm{O}_{4}$.

4.1.1.2. Crystalline structure - X-ray diffraction pattern. The XRD patterns of PGMA, PPA-PGMA and PPA-PGMA/Fe ${ }_{3} \mathrm{O}_{4}$ are displayed in Fig. S4 (see Annex B-a for more details). The XRD pattern is the representative of the cubic spinel structure of $\mathrm{Fe}_{3} \mathrm{O}_{4}$ (Stoia et al., 2016). Using the highest intense peak corresponding to (311) index, the size was found to be about $7.65 \mathrm{~nm}$ (using the Scherrer equation).

4.1.1.3. Magnetic properties - vibrating sample magnetometry. The magnetic properties of the sorbent are deeply discussed in Annex B-b. Fig. S5 displays the magnetization loop: the coercivity and retentivity coefficients are negligible (Liu et al., 2006). The coercivity is close to $196 \mathrm{G}$ (i.e., $19.6 \mathrm{mT}$ ) while the retentivity (or remanent magnetization) tends to $2.8 \mathrm{emu} \mathrm{g}^{-1}$ i.e. the PPA-PGMA/ $\mathrm{Fe}_{3} \mathrm{O}_{4}$ nanocomposites are super-paramagnetic with saturation magnetization close to $18.2 \mathrm{emu}^{-1}$.

4.1.1.4. Textural properties - BET surface analysis. The textural properties are detailed in Annex B-c. Fig. S6 shows the $\mathrm{N}_{2}$ sorptiondesorption isotherms for PPA-PGMA/ $/ \mathrm{Fe}_{3} \mathrm{O}_{4}$ and the sorbent has a weak SSA (close to $5 \mathrm{~m}^{2} \mathrm{~g}^{-1}$ ) with a reduced porous volume (close to $\left.0.017 \mathrm{~cm}^{3} \mathrm{~g}^{-1}\right)$; the average pore size is near $14 \mathrm{~nm}$.

4.1.1.5. Thermogravimetric analysis - TGA/DTG. The detailed discussion of thermal degradation steps for PGMA, PPA-PGMA and PPA-PGMA/ $/ \mathrm{Fe}_{3} \mathrm{O}_{4}$ is documented in Annex B-d. Fig. S7 shows the TGA and DTG profiles of these materials. The incorporation of magnetite significantly improves the thermal stability of the composite. The magnetic $\mathrm{Fe}_{3} \mathrm{O}_{4}$ core prevents the complete thermal degradation of the PPA-PGMA; the residual weight fraction of $\mathrm{Fe}_{3} \mathrm{O}_{4}$ in the end product equals the fraction of magnetite in the sorbent ( $\approx 20 \%$ ). It is noteworthy that the initial mass ratio between magnetic particles and functionalized resin (before milling) (i.e., 1:2) would suggest a theoretical mass fraction of magnetite in the composite close to $33 \%$, which is consistent with the final degradation yield close to $38 \%$ but differs from the differential weight loss between PPA-PGMA and PPA-PGMA/ $\mathrm{Fe}_{3} \mathrm{O}_{4}$.

\subsubsection{Chemical characterization}

4.1.2.1. Elemental analysis. Table $\mathrm{S} 2$ reports the elemental analysis of the different materials (PGMA, TA-PGMA, PPA-PGMA and PPA$\mathrm{PGMA} / \mathrm{Fe}_{3} \mathrm{O}_{4}$ ) and the detailed discussion is in Annex $\mathrm{C}-\mathrm{a}$. The preparation of the PPA-PGMA was previously discussed (Galhoum et al., 2019). As expected, after incorporating magnetite fraction the phosphorus content decreases from $4.9 \%$ (i.e., $1.58 \mathrm{mmol} \mathrm{P} \mathrm{g}^{-1}$ ) to $3.15 \%$ (i.e., $1.02 \mathrm{mmol} \mathrm{P} \mathrm{g}^{-1}$ ). The decrease (i.e., $35 \%$ ) is consistent with the respective initial proportions of magnetite and polymer compounds in the high-energy milling reactor, but this decrease differs from conclusions deduced from TGA analysis.

4.1.2.2. FTIR spectroscopy. Fig. S8 shows the FTIR spectra of PGMA, TA-PGMA, PPA-PGMA, and PPA-PGMA/ $\mathrm{Fe}_{3} \mathrm{O}_{4}$. The functionalization of PGMA was already discussed (Galhoum et al., 2019) (see also Annex A \& C-b for more details). After ball milling of PPA-PGMA with magnetite, a new IR peak appears at $557 \mathrm{~cm}^{-1}$ which is attributed to $\mathrm{Fe}-\mathrm{O}$ lattice vibrational stretching in $\mathrm{Fe}_{3} \mathrm{O}_{4}$ (Xiao et al., 2019).

4.1.2.3. XPS analysis (Figs. S9a-c). Fig. 2a shows the XPS survey of PGMA, PPA-PGMA microparticles and PPA-PGMA/Fe ${ }_{3} \mathrm{O}_{4}$. Fig. S9 reports the high-resolution XPS spectra (HRES) of representative 


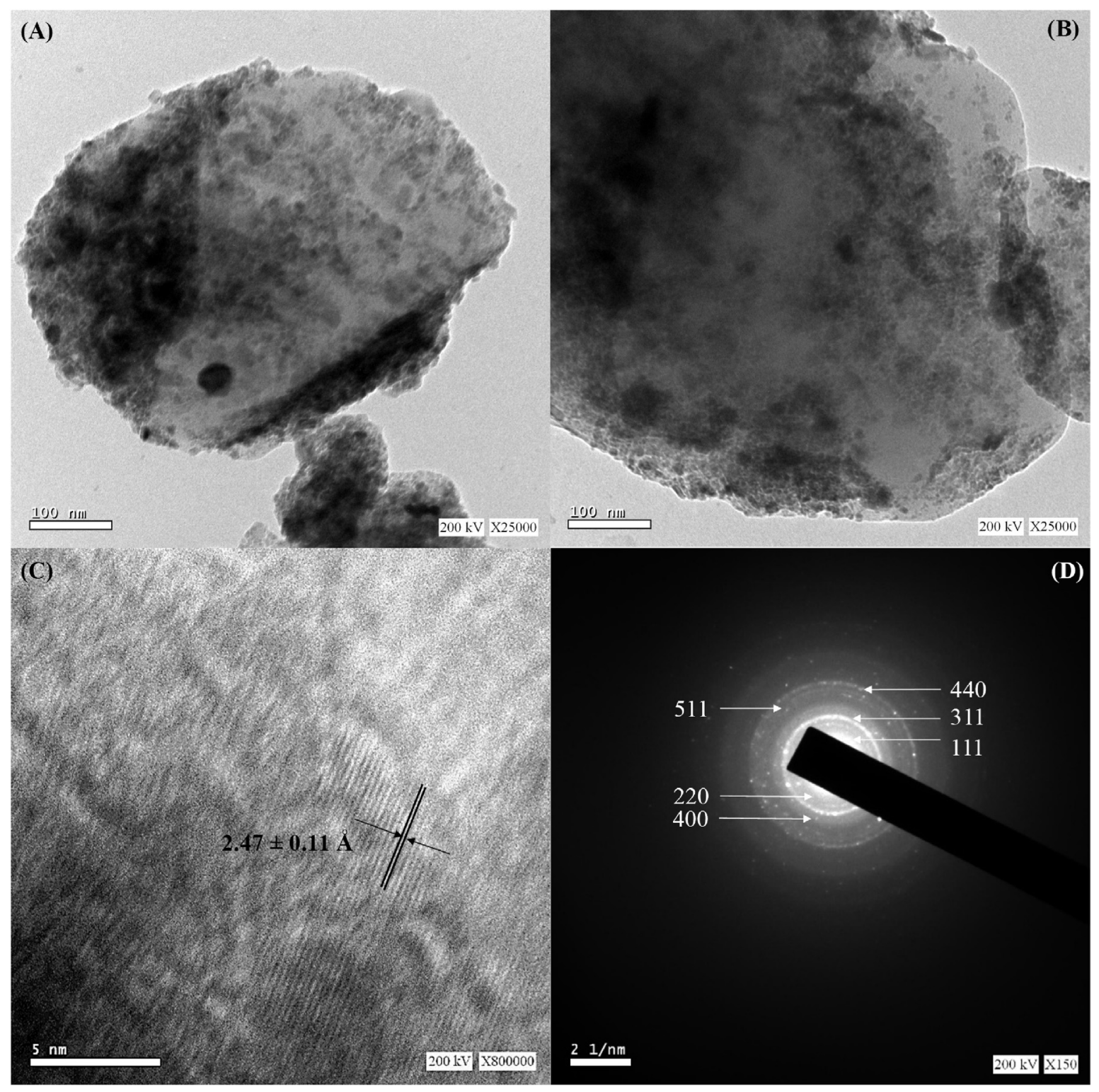

Fig. 1. Structure of the nanocomposite sorbent - the TEM microphotographs (A \& B), crystal lattice (C) and selected area electron diffraction pattern, SAED (D).

signals of main elements identified on the materials. The XPS characterizations of PGMA and PPA-PGMA have been documented on PGMA and PPA-PGMA microparticles (Galhoum et al., 2019). The survey spectra clearly identify the successive modifications of the composition of the materials: the phosphonomethylation of PGMA is confirmed by the appearance of $\mathrm{P} 2 p$ and $\mathrm{P} 2 s$ at binding energies (BEs) $134 \mathrm{eV}$ and $198 \mathrm{eV}$, respectively. Traces of chlorine are also identified on functionalized polymer ( $\mathrm{Cl} L M M$ at $1313 \mathrm{eV})$. After synthesizing the core-shell nanocomposite the XPS survey allows identifying a series of signals of Fe: Fe $L M M$ at $785 \mathrm{eV}$, Fe $2 p$ in the range $70-730 \mathrm{eV}$, Fe $3 s$ at $96 \mathrm{eV}$, Fe $3 p$ at $58 \mathrm{eV}$. Table S3 summarizes the assignments (and relative atomic fractions) of the deconvoluted bands for $\mathrm{C} 1 s, \mathrm{O} 2 s, \mathrm{~N} 1 s, \mathrm{P} 2 p$ and Fe $2 p$ signals (from HRES spectra):

(a) C $1 s$ signal is hardly affected by the functionalization and the incorporation of magnetite.

(b) $01 \mathrm{~s}$ signal shows the increase of the intensity of the band at $531.7 \mathrm{eV}$ after functionalization of PGMA (due to the appearance of $\mathrm{P}-\mathrm{O}$ function); a new band at $530.3 \mathrm{eV}$ appears with incorporation of magnetite (Lattice $O$ signal for magnetite).

(c) $\mathrm{N} 1 \mathrm{~s}$ appears after phosphonomethylation through the intermediary grafting of DETA; the relative intensity of the band at $400.8 \mathrm{eV}\left(-\mathrm{NH}_{2},>\mathrm{NH}\right)$ is increased (associated with a deprotonation of the polymer) and surprisingly a new (weak) peak appears after incorporation of magnetite (possibly assigned to $\mathrm{C}-\mathrm{N}$ bond). The reasons for these changes are not clearly identified.

(d) P $2 p$ signal confirms the phosphonomethylation of PGMA with co-existence of $\mathrm{P}-\mathrm{O}, \mathrm{P}-\mathrm{C} / \mathrm{PO}_{4}$ and protonated phosphonate bonds; after incorporation of magnetite the relative distribution between the different bonds changes with relative increase of the intensity of protonated phosphonate (and the weakening of signals associated with $\mathrm{C} / \mathrm{PO}_{4}$ bonds).

(e) Fe $2 p$ signal appearing on PPA-PGMA/ $\mathrm{Fe}_{3} \mathrm{O}_{4}$ sorbent can be deconvoluted in three signals (accompanied by their doublet signal) corresponding to $\mathrm{Fe}(\mathrm{III})$ under both octahedral and 

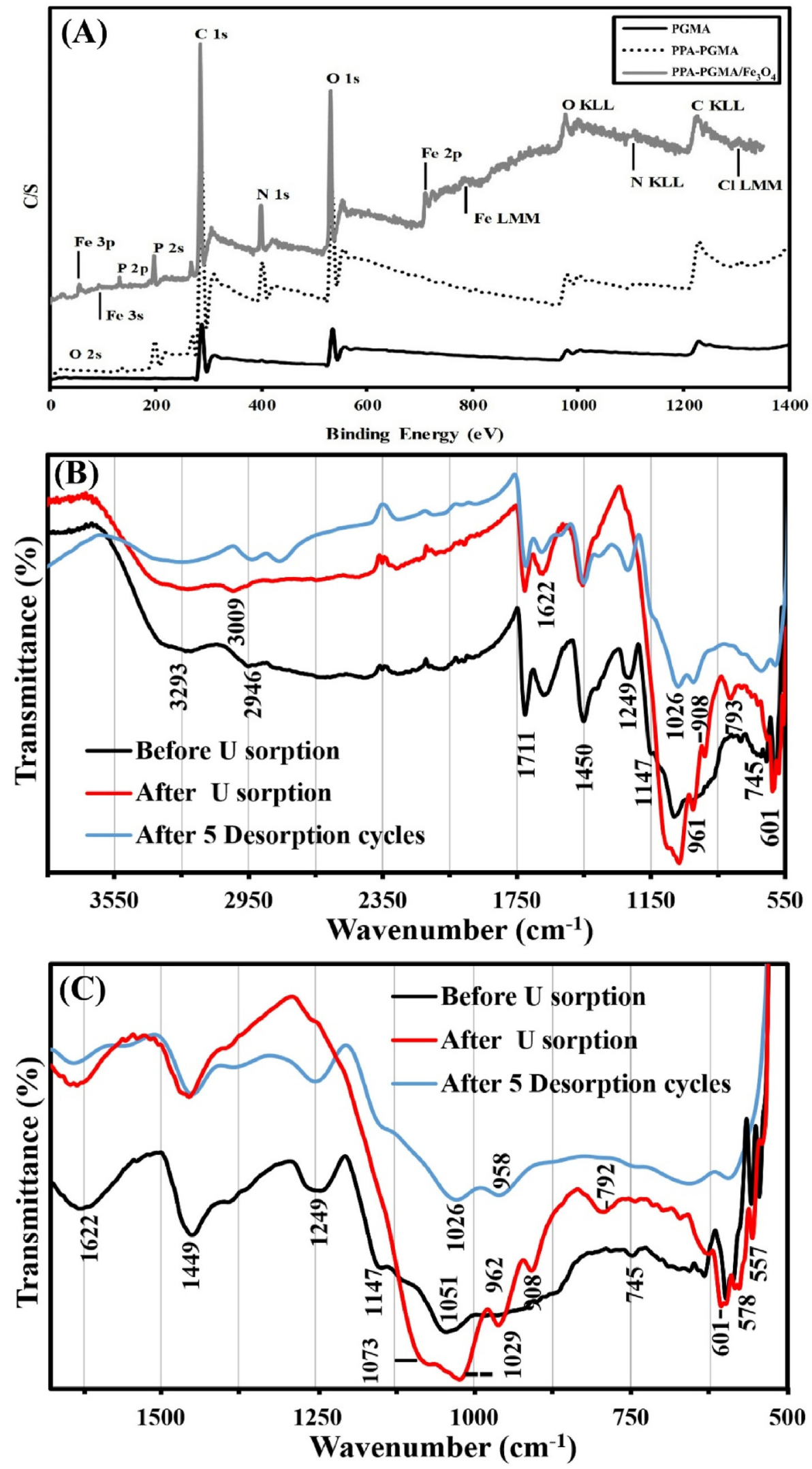

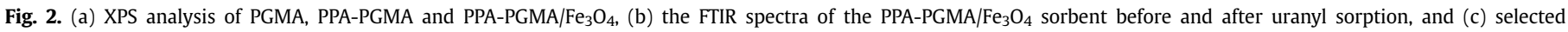
wavenumber ranges. 
tetrahedral forms, and Fe(II) (octahedral form). The relevant satellite bands are not well resolved. The Fe $2 p 3 / 2$ band is identified at $710.6 \mathrm{eV}$; this band may be assigned to either $\mathrm{Fe}_{3} \mathrm{O}_{4}$ or $\gamma-\mathrm{Fe}_{2} \mathrm{O}_{3}$ (maghemite) compounds (Kong et al., 2010).

4.1.2.4. pHPZC determination. Annex C-c and Fig. S10 report the titration profile of PGMA, TA-PGMA, PPA-PGMA, and PPA-PGMA/ $\mathrm{Fe}_{3} \mathrm{O}_{4}$ in consistent with these successive steps. Table $\mathrm{S} 4$ summarizes their $\mathrm{pH}_{\mathrm{PZC}}$ values. The incorporation of the magnetic core in the sorbent particle (PPA-PGMA/ $\mathrm{Fe}_{3} \mathrm{O}_{4}$ ) hardly affects the $\mathrm{pH}_{\mathrm{PZC}}$ that is close to 2.83 (little higher than the $\mathrm{PH}_{\mathrm{PZC}}$ of PPA-PGMA; i.e., 2.69).

\subsubsection{Interaction with uranyl species}

Fig. 2 (b, c) shows the FTIR spectra of the PPA-PGMA/Fe $\mathrm{O}_{3}$ sorbent before and after uranyl sorption. After metal sorption, the band at $2936 \mathrm{~cm}^{-1}$ is shifted to $3009 \mathrm{~cm}^{-1}$ and its intensity tends to decrease. This band is assigned to $-\mathrm{NH}_{2}$ groups, the shift after uranyl sorption clearly confirms the contribution of amine groups in metal binding (Galhoum et al., 2019). The band representative of $-\mathrm{OH}$ (identified at $3293 \mathrm{~cm}^{-1}$ ) is not affected by uranyl binding. The characteristic peak of $\mathrm{UO}_{2}^{2+}$ appears at $793 \mathrm{~cm}^{-1}$ (James et al., 2009; Wang et al., 2012), and this band disappears after metal desorption. This is further proved by the presence of IR signal of uranyl at $908 \mathrm{~cm}^{-1}$ (representing the vibration of the linear $\mathrm{O}=\mathrm{U}=$ $\mathrm{O}$ group). The peak at $1249 \mathrm{~cm}^{-1}$, assigned to $\mathrm{v}(-\mathrm{P}=\mathrm{O})$, nearly disappears after uranyl ion sorption (Sureshkumar et al., 2010). This is a clear evidence that the chemical environment of the $\mathrm{P}=\mathrm{O}$ bond is affected by metal binding; uranyl ions binding involves phosphonate reactive groups. The relative intensity of the peak $(-\mathrm{P}=\mathrm{O})$ at $745 \mathrm{~cm}^{-1}$ decreases with metal binding. The change of the absorption peaks in the fingerprint region indicated that phosphonate functional groups also participate in the reaction of uranium. The peak at $1147 \mathrm{~cm}^{-1}$ (assigned to stretching vibration of $-\mathrm{C}=\mathrm{O}$ ) also disappears. The comparison of the spectra (raw and after 5 cycles) confirm that the spectrum of the sorbent was hardly affected by the successive operations: the sorbent is remarkably stable; this is confirming the stability of sorption/desorption performances.

Based on FTIR data, it is possible concluding that uranyl ions bind on the core-shell nanocomposite through interactions with phosphonic groups rather than amine groups (Sureshkumar et al., 2010).

The coordination of $\mathrm{UO}_{2}^{2+}$ may involve four, five or six donor atom (Rao et al., 2006; Xie et al., 2019). By analogy with the mechanism reported for $\mathrm{La}(\mathrm{III})$ and $\mathrm{Y}(\mathrm{III})$ sorption on PPA-PGMA (Galhoum et al., 2019), a tentative mechanism can be proposed for $\mathrm{U}(\mathrm{VI})$ uptake (scheme $2 \mathrm{c}$ ); consisting of the coordination of $\mathrm{U}(\mathrm{VI})$ to the ligand on a tetradentate mode. The binding of metal ions takes place through: (a) ionic bond with one deprotonated oxygen atom of phosphonate group (b) two coordinating bonds with nitrogen donors of amine groups, and (c) one bond coordinates with one oxygen donor of $\mathrm{OH}$ groups.

It is noteworthy that the spectrum of the material after being used for five sorption/desorption cycles is similar to the raw material spectrum. This means that the uranyl desorption is successful and that the sorbent remains remarkably stable.

\subsection{Sorption properties}

\subsection{1. $p H$ effect}

The effect of $\mathrm{pH}$ on metal sorption may be influenced by different parameters, including metal speciation, metal precipitation (beginning with the formation of colloidal species), protonation/deprotonation of reactive groups, and sorbent stability (this may be the case for magnetite core at pH below 1.3). Fig. 3a shows the effect of equilibrium $\mathrm{pH}$ on sorption capacity. The sorption progressively increases with $\mathrm{pH}$ between 1 and 3; the sorption capacity stabilizes up to 3.5 and decreases above $\mathrm{pH} 3.5$. It is noteworthy that initial $\mathrm{pH}$ remains unchanged between $\mathrm{pH} 2$ and 3 , while above, the equilibrium $\mathrm{pH}$ tends to linearly decrease: at $\mathrm{pH}_{0}$ close to 6 , the $\mathrm{pH}$ decreases by about 2 units. This $\mathrm{pH}$ variation may be explained by the release of protons during the sorption process and/or by the binding of hydrolyzed uranyl species. It is noteworthy that the $\mathrm{pH}$ variation in the presence of uranyl is more observable compared with that recorded for the determination of pH PZC (Fig. S10).

The optimum $\mathrm{pH}$ is confirmed by the change in the slope of the curve representing (in $\log _{10}$ units) the distribution ratio $\mathrm{D}\left(\mathrm{q}_{\mathrm{eq}} / \mathrm{C}_{\mathrm{eq}}\right.$, $\mathrm{L} \mathrm{g}^{-1}$ ) in function of $\mathrm{pH}$ (Fig. S11). Below $\mathrm{pH} \mathrm{3,} \mathrm{the} \mathrm{sorption} \mathrm{is}$ enhanced (positive slope close to +0.71 ) while above this limit value the recovery of uranyl decreases (negative slope close to -0.25 ). This is an indication on the stoichiometric exchange (release or binding) of protons with uranyl uptake on the different $\mathrm{pH}$ ranges. This $\mathrm{pH} 3$ value is remarkably close to the $\mathrm{pH}_{\mathrm{PzC}}$ of the magnetic sorbent (i.e., 2.69): the acid-base properties and overall charge of PPA-PGMA/ $/ \mathrm{Fe}_{3} \mathrm{O}_{4}$ (positively charged at $\mathrm{pH}$ below 2.7) directly influence its efficiency for $\mathrm{U}(\mathrm{VI})$ binding. Fig. S12a displays the metal species distribution (under the experimental conditions of the experience: $\mathrm{pH}$ controlled with sulfuric acid and uranyl acetate salt) in function of the $\mathrm{pH}$. Under acidic conditions (i.e., $\mathrm{pH}$ below 2), (neutral) uranyl sulfate species $\left(\mathrm{UO}_{2} \mathrm{SO}_{4}\right)$ predominates (60-70\%), with the presence of free (cationic) uranyl species (20-30\%) and (anionic) uranyl sulfate species (i.e., $\mathrm{UO}_{2}\left(\mathrm{SO}_{4}\right)_{2}^{2-}$ ) coexist (beginning negligible with $\mathrm{pH}$ increase). Between $\mathrm{pH} 2$ and 4 , the fraction of free uranyl species increases with progressive disappearance of neutral uranyl sulfate. Above $\mathrm{pH} 4$, polynuclear hydrolyzed species progressively predominate (i.e., mainly $\left.\left(\mathrm{UO}_{2}\right)_{2}(\mathrm{OH})_{2}^{2+},\left(\mathrm{UO}_{2}\right)_{3}(\mathrm{OH})_{5}^{+},\left(\mathrm{UO}_{2}\right)_{4}(\mathrm{OH})_{7}^{\frac{1}{7}},\left(\mathrm{UO}_{2}\right)_{3}(\mathrm{OH})_{4}^{2+}\right)$; cationic species (including $\mathrm{UO}_{2}(\mathrm{OH})^{+}$) represent more than $90 \%$ of total uranium. Therefore, in strong acidic solutions (i.e., $\mathrm{pH} \mathrm{1-2)} \mathrm{the}$ sorption may occurs through electrostatic attraction of anionic uranyl sulfate on free protonated amine groups, by coordination of free uranyl species on partially protonated phosphonate groups and by ligand exchange (sulfate on neutral uranyl sulfate). However, the competition of protons, limits the sorption (below $50 \mathrm{mg} \mathrm{U} \mathrm{g}^{-1}$ ). When $\mathrm{pH}$ reaches 3 , the sorption capacity reaches its maximum value $\approx 90 \mathrm{mg} \mathrm{U} \mathrm{g}^{-1}$ (under selected experimental conditions): the progressive deprotonation of amine and phosphonate groups (overall negative charge) improves the affinity for uranyl species (mainly as free uranyl species). FTIR analyses have confirmed the strong impact of uranyl binding on phosphonate groups (preferentially to amine groups) (Fig. 3b). When the $\mathrm{pH}$ increases above $\mathrm{pH}$ $3.5-4$, the sorption capacity tends to slightly decrease, this is probably associated with the formation of polynuclear hydrolyzed species, with more difficulties in ligand exchange and for binding on phosphonate groups (steric hindrance, etc.). The $\mathrm{pH}$ increase with uranyl sorption due to proton release (and to a lesser extent, the binding of hydrolyzed species with subsequent displacement in uranyl speciation). Above $\mathrm{pH} \mathrm{5}$, under selected experimental conditions, uranyl begins to precipitate. For these reasons, additional experiments were performed at $\mathrm{pH}=4$; after sorption, the $\mathrm{pH}$ stabilizes in the range 3.4 (equilibrium $\mathrm{pH}$ affected by metal concentration).

\subsubsection{Uptake kinetics}

The investigation of uptake kinetics shows that pseudoequilibrium is reached within $120 \mathrm{~min}$ (under selected experimental conditions) (Figure b). Different steps in the process can be 

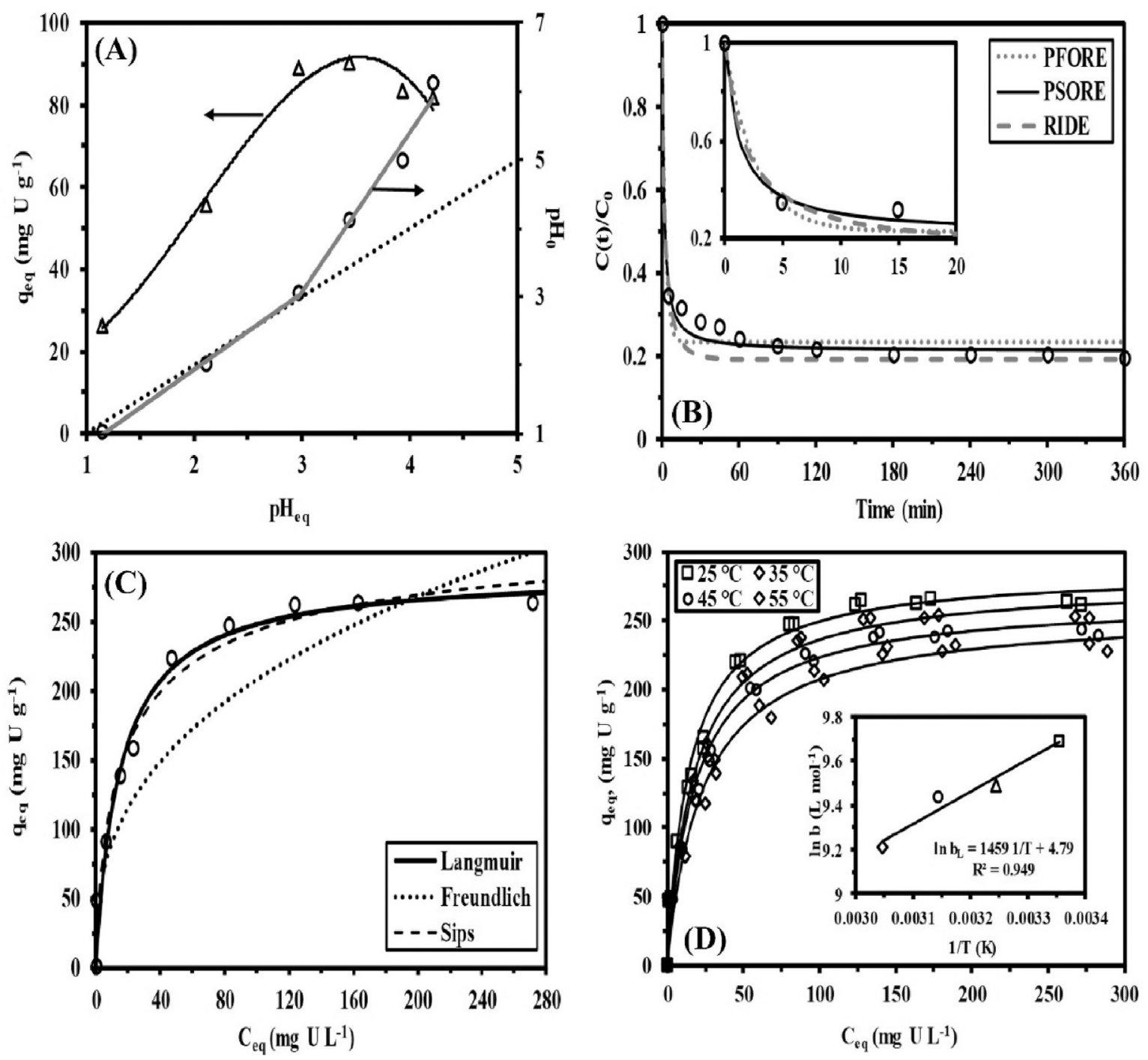

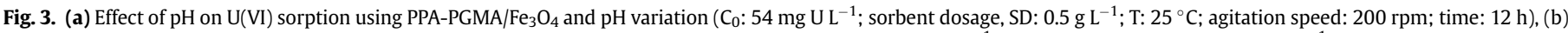

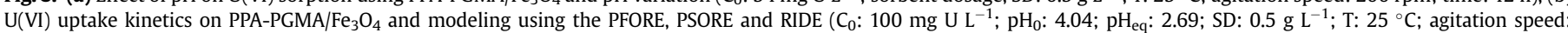

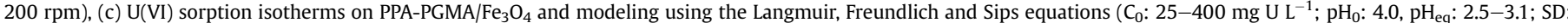

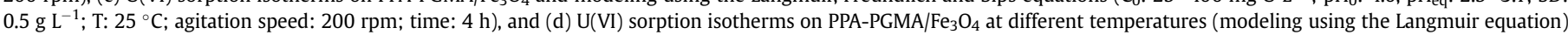
and Van't Hoff plot (insert) ( $\mathrm{C}_{0}: 25-400 \mathrm{mg} \mathrm{U} \mathrm{L}{ }^{-1} ; \mathrm{pH}_{0}: 4.0, \mathrm{pH}_{\mathrm{eq}}$ : 2.4-3.2; SD: $0.5 \mathrm{~g} \mathrm{~L}^{-1}$; $\mathrm{T}$ : $25-45^{\circ} \mathrm{C}$; agitation speed: $200 \mathrm{rpm}$; time: $4 \mathrm{~h}$ ).

identified:

(a) in the fast initial step (within the first 5 min of contact) the sorbent removes about $82 \%$ of total sorption ( $\mathrm{q}_{\mathrm{eq}}$ ),

(b) the second step (lasting between 5 min and 60 min) leads to a complementary sorption representing about $12 \%$ of total sorption, and

(c) the final slow step accounts for 6\%; the sorbent remove about $4 \%$ of $\mathrm{q}_{\mathrm{eq}}$ after 120 min of contact (cumulative percentage: 98\%). It is necessary waiting for $6 \mathrm{~h}$ to reach the real equilibrium.

Fig. S13 shows the modeling of kinetic profiles with the simplified model of resistance to intraparticle diffusion Weber and Morris (Table S1 for model, Fig. S13 for relevant parameters) (Weber and Morris, 1963). Three linear segments can be identified corresponding to the three steps reported above. The first step corresponds to the fast sorption on the reactive groups (phosphonate and amine groups) the most accessible at the surface of nanoparticles. In the second step of the process, the gradient of concentration between the solution and the sorbent has decreased and the driving force for the mass transfer of uranyl ions to the internal reactive groups (first internal layers and/or larger pores of the structured material) is slowed down. In the last step of the process, the sorption is controlled by the resistance to intraparticle diffusion; more specifically through very thin pores, as demonstrated by textural analysis (Fig. S6).

The kinetic profiles can be fitted by conventional models such as the pseudo-first order rate equation (PFORE), the pseudo-second order rate equation (PSORE) and the resistance to intraparticle diffusion equation (Crank equation, RIDE) (Table S1). PFORE and PSORE equations developed for homogeneous chemical reactions are used for describing heterogeneous reactions under the hypothesis that the apparent rate coefficients are implicitly function of resistance to diffusions (bulk, film and intraparticle diffusions). Fig. 3b shows the fits of experimental curves with the parameters summarized in Table 1. All the models fail to simulate the profiles at least in the highest curvature range. The comparison of correlation 
Table 1

Modeling of uptake kinetics for $\mathrm{U}(\mathrm{VI})$ sorption using PPA-PGMA/Fe ${ }_{3} \mathrm{O}_{4}-$ PFORE, PSORE and RIDE equations.

\begin{tabular}{|c|c|c|c|c|c|c|c|c|}
\hline \multirow[b]{2}{*}{$\mathrm{q}_{\text {eq,exp }}$} & \multicolumn{3}{|l|}{ PFORE } & \multicolumn{3}{|l|}{ PSORE } & \multicolumn{2}{|l|}{ RIDE } \\
\hline & $\mathrm{q}_{\mathrm{eq}, 1}$ & $\mathrm{k}_{1} \times 10^{1}$ & $\mathrm{R}^{2}$ & $\mathrm{q}_{\mathrm{eq}, 2}$ & $\mathrm{k}_{2} \times 10^{3}$ & $\mathrm{R}^{2}$ & $\mathrm{D}_{\mathrm{e}} \times 10^{9}$ & $\mathrm{R}^{2}$ \\
\hline $\mathrm{mg} \mathrm{U} \mathrm{g}^{-1}$ & $\mathrm{mg} \mathrm{U} \mathrm{g}^{-1}$ & $\min ^{-1}$ & & $\overline{\mathrm{mg} \mathrm{U} \mathrm{g}^{-1}}$ & $\mathrm{~L} \mathrm{mg}^{-1} \min ^{-1}$ & & $\mathrm{~m}^{2} \min ^{-1}$ & \\
\hline 157.9 & 151.7 & 3.82 & 0.973 & 155.7 & 5.21 & 0.989 & 3.38 & 0.977 \\
\hline
\end{tabular}

coefficients shows that the PSORE is a little better than RIDE (and even more PFORE). This is confirmed by the comparison of calculated qeq,i values with experimental sorption capacity qeq,exp.: the value is closer for the PSORE than for the PFORE. The PSORE is frequently associated to chemisorption processes (though a good mathematical fit does not necessarily prove that the supporting physical and chemical hypotheses are validated). The RIDE allows approaching the effective diffusion coefficient $\left(D_{e}\right)$, which is close to $3.4 \times 10^{-9} \mathrm{~m}^{2} \mathrm{~min}^{-1}$. This value is about one order of magnitude lower than the self-diffusivity of uranyl ions in water (i.e; , $2.56 \times 10^{-8} \mathrm{~m}^{2} \mathrm{~min}^{-1}$ ) (Marcus, 1997). The resistance to intraparticle diffusion has a limited effect on mass transfer, especially compared with the sorption of $\mathrm{La}$ (III) and Y(III) using PPA-PGMA beads, where the effective diffusivity coefficients were found close to $1.39 \times 10^{-11} \mathrm{~m}^{2} \mathrm{~min}^{-1}$ and $2.07 \times 10^{-11} \mathrm{~m}^{2} \mathrm{~min}^{-1}$, respectively (Galhoum et al., 2019). Lower diffusivity coefficients were found for $\mathrm{U}(\mathrm{VI})$ transfer through amidoxime resins (i.e., 0.66$1.08 \times 10^{-11} \mathrm{~m}^{2} \mathrm{~min}^{-1}$ ) (Das et al., 2009) extractant-impregnated membrane (i.e., $5.36 \times 10^{-10} \mathrm{~m}^{2} \mathrm{~min}^{-1}$ ) (Kedari et al., 2013) or bituminous shales (i.e., 4.8-18.0 $\times 10^{-9} \mathrm{~m}^{2} \mathrm{~min}^{-1}$ ) (Ortaboy and Atun, 2014),

\subsubsection{Sorption isotherms and thermodynamics}

Fig. $3 c$ shows the sorption isotherms at $\mathrm{pH}_{0} 4$ (equilibrium $\mathrm{pH}$ varied between 3.1 and 2.7; being stronger at high metal concentration). The isotherm is characterized by the steep initial section, which confirms the high affinity of the sorbent for uranyl and by the saturation plateau reached at residual concentration close to $120 \mathrm{mg} \mathrm{U} \mathrm{L}^{-1}$ : the maximum sorption capacity reaches $262 \mathrm{mg} \mathrm{U}$ $\mathrm{g}^{-1}$ (i.e., $1.1 \mathrm{mmol} \mathrm{U} \mathrm{g}^{-1}$ ). The molar concentration of $\mathrm{P}$ (phosphonate moiety) and $\mathrm{N}$ (amine groups from DETA) are respectively $1.01 \mathrm{mmol} \mathrm{P} \mathrm{g}^{-1}$ and $3.3 \mathrm{mmol} \mathrm{N} \mathrm{g}^{-1}$. This is consistent with the tetradentate binding mechanism suggested in section 3.1.3., two other positions on $\mathrm{U}(\mathrm{VI})$ being occupied by two water bound molecules. This is also consistent with the molecular modeling reported for $\mathrm{Y}(\mathrm{III})$ and $\mathrm{La}(\mathrm{III})$ binding on PPA-PGMA beads (Galhoum et al., 2019).

The lines represent the modeling of experimental profiles with conventional equations (i.e., Langmuir, Freundlich and Sips equations, Table S1); Fig. S14 shows modeling of experimental data with the Dubinin-Radushkevich equation (D-R model). Parameters of the different models are summarized in Table 2 (or directly in Fig. S14 for D-R equation). The Freundlich equation being a powerlike function does not fit the saturation plateau of the isotherm. The comparison of both the determination coefficients $\left(R^{2}\right)$ and the $\mathrm{q}_{\mathrm{m} \text {,calc }}$ values (compared with experimental value) allows concluding that the introduction of the third adjustable parameter in the Sips equation does not improve mathematical fit. In addition, the calculated maximum sorption capacity is strongly overevaluated while for Langmuir equation the over-estimation does not exceed $10 \%$. Langmuir equation is more appropriate for modeling experimental profile. The hypotheses of the Langmuir model suggest that sorption occurs as a monolayer at the surface of the sorbent and that the sorbate is bound to the surface with identical binding energies (i.e., the sorbent can be considered homogeneous). The favorability of the sorption is evaluated using the dimensionless constant $\left(\mathrm{R}_{\mathrm{L}}=\left(1+\mathrm{b}_{\mathrm{L}} \times \mathrm{C}_{0}\right)^{-1}\right)$, where $\mathrm{b}_{\mathrm{L}}$ is the Langmuir constant and $\mathrm{C}_{0}$ the initial metal concentration. $\mathrm{R}_{\mathrm{L}}$ varies between 0.38 and $9.6 \times 10^{-6}$; being systematically lower than 1 , uranyl sorption on PPA-PGMA/ $\mathrm{Fe}_{3} \mathrm{O}_{4}$ is highly favorable. The systems that are driven by physical or chemical sorption are routinely discriminated using the Dubinin-Radushkevich. Fig. S14 show the D-R mathematical fit of experimental profile, which is relatively poor $\left(R^{2}: 0.894\right)$; therefore, the calculation of the binding energy $\left(E_{\mathrm{ad}}, \mathrm{kJ} \mathrm{mol}^{-1}\right.$ ) should be considered as indicative. The sorption energy is close to $8.33 \mathrm{~kJ} \mathrm{~mol}^{-1}$; this means very close to the discriminating value (i.e., $8 \mathrm{~kJ} \mathrm{~mol}^{-1}$ ). This is indicative of a system controlled by chemisorption. This agrees well with the good fitting of kinetic data using the pseudo-second order rate relation (which is related to the chemical sorption).

The comparison of $\mathrm{U}(\mathrm{VI})$ sorption at different temperatures (25-55 ${ }^{\circ} \mathrm{C}$, under similar experimental conditions) shows a progressive decrease in sorption capacity (Fig. S15); the sorption process is exothermic. In order to evaluate more accurately the thermodynamic constants, complete sorption isotherms were performed at $35{ }^{\circ} \mathrm{C}$ and $45{ }^{\circ} \mathrm{C}$ (Fig. 3d). The sorption capacity at monolayer saturation decreases an increase in temperature, as a confirmation of the exothermic behavior of uranyl binding. The Langmuir equation was used for fitting experimental profiles; Table 3 reports the relevant parameters, including the affinity coefficient (i.e., $b_{\mathrm{L}}, \mathrm{mg} \mathrm{U} \mathrm{g}^{-1}$ ). After converting $\mathrm{b}_{\mathrm{L}}$ in molar units, the Van't Hoff equation (Eq. (1)) was used for calculating thermodynamic parameters $\left(\Delta \mathrm{H}^{\circ}\right.$, enthalpy change, $\mathrm{kJ} \mathrm{mol}^{-1} ; \Delta \mathrm{S}^{\circ}$, entropy change, $\mathrm{J} \mathrm{mol}^{-1} \mathrm{~K}^{-1}$ ).

$\ln \mathrm{b}_{\mathrm{L}}=-\frac{\Delta H^{o}}{R T}+\frac{\Delta \mathrm{S}^{\mathrm{o}}}{\mathrm{R}}$

where $\mathrm{R}$ is the ideal gas constant and $\mathrm{T}$ the absolute temperature.

The enthalpy change approaches $-12.2 \mathrm{~kJ} \mathrm{~mol}^{-1}$, while the entropy change is close to $39.8 \mathrm{~J} \mathrm{~mol}^{-1} \mathrm{~K}^{-1}$. The negative value of enthalpy change confirms the exothermic behavior of uranyl binding on PPA-PGMA/Fe $\mathrm{Fe}_{3} \mathrm{O}_{4}$. On the other hand, the positive value of entropy change means that the disorder of the system increases

Table 2

Modeling of sorption isotherms for $\mathrm{U}(\mathrm{VI})$ sorption using Langmuir, Freundlich and Sips equations.

\begin{tabular}{|c|c|c|c|c|c|c|c|c|c|c|}
\hline \multirow[b]{2}{*}{$\mathrm{q}_{\mathrm{m}, \exp }$} & \multicolumn{3}{|c|}{ Langmuir } & \multicolumn{3}{|c|}{ Freundlich } & \multirow[b]{2}{*}{$\mathrm{q}_{\mathrm{m}, \mathrm{s}}$} & \multirow[b]{2}{*}{$\mathrm{b}_{\mathrm{S}} \times 10^{2}$} & \multicolumn{2}{|l|}{ Sips } \\
\hline & $\mathrm{q}_{\mathrm{m}, \mathrm{L}}$ & $\mathrm{b}_{\mathrm{L}} \times 10^{2}$ & $\mathrm{R}^{2}$ & $\mathrm{k}_{\mathrm{F}}$ & $\mathrm{n}$ & $\mathrm{R}^{2}$ & & & $\mathrm{n}$ & $\mathrm{R}^{2}$ \\
\hline 266.0 & 286.2 & 6.79 & 0.987 & 71.2 & 3.89 & 0.949 & 307.6 & 10.2 & 1.25 & 0.987 \\
\hline
\end{tabular}

$\mathrm{q}_{\mathrm{m}, \mathrm{i}}: \mathrm{mg} \mathrm{U} \mathrm{g}^{-1} ; \mathrm{b}_{\mathrm{i}}: \mathrm{L} \mathrm{mg}^{-1}$. 
Table 3

Effect of temperature on $\mathrm{U}(\mathrm{VI})$ sorption isotherms using PPA-PGMA/Fe ${ }_{3} \mathrm{O}_{4}-$ Modeling with Langmuir equation.

\begin{tabular}{|c|c|c|c|c|}
\hline Temperature $\left({ }^{\circ} \mathrm{C}\right)$ & $\mathrm{q}_{\mathrm{m}, \exp }\left(\mathrm{mg} \mathrm{U} \mathrm{g}^{-1}\right)$ & $\mathrm{q}_{\mathrm{m}, \mathrm{L}}\left(\mathrm{mg} \mathrm{U} \mathrm{\textrm {g } ^ { - 1 } )}\right.$ & $\mathrm{b}_{\mathrm{L}} \times 10^{2}\left(\mathrm{~L} \mathrm{mg}^{-1}\right)$ & $\mathrm{R}^{2}$ \\
\hline 25 & 266 & 286.2 & 6.79 & 0.987 \\
\hline 35 & 254 & 278.7 & 5.55 & 0.987 \\
\hline 45 & 244 & 265.6 & 5.28 & 0.987 \\
\hline 55 & 233 & 256.9 & 4.20 & 0.981 \\
\hline
\end{tabular}

with uranyl sorption; probably due to dehydration mechanisms of uranyl species and release of $\mathrm{H}_{2} \mathrm{O}$ molecules. The Gibbs free energy $\left(\Delta \mathrm{G}^{\circ}, \mathrm{kJ} \mathrm{mol}^{-1}\right)$ is deduced from Eq. (2).

$\Delta \mathrm{G}^{\mathrm{O}}=\Delta H^{0}-T \Delta \mathrm{S}^{\mathrm{O}}$

The Gibbs energy varies between -24.0 and $-24.8 \mathrm{~kJ} \mathrm{~mol}^{-1}$. Its negative value means that the reaction is spontaneous. The absolute value of free Gibbs energy $\left(\Delta G^{0}\right)$ is systematically greater than the absolute value of I $\mathrm{T} \Delta \mathrm{S}^{\circ}$ ।; this means that the sorption of uranyl on PPA-PGMA/ $\mathrm{Fe}_{3} \mathrm{O}_{4}$ is controlled by enthalpy change rather than by entropy change.

Table S5 compares the sorption properties of PPA-PGMA/Fe $\mathrm{O}_{4}$ for uranyl with those reported for alternative sorbents and biosorbents. The strict comparison is made difficult by different experimental conditions (and more specifically the $\mathrm{pH}$ ); however, in the range of $\mathrm{pH}$ investigated in this study (i.e., $\mathrm{pH} 3-5$ ) PPA$\mathrm{PGMA} / \mathrm{Fe}_{3} \mathrm{O}_{4}$ is part of the materials having the best sorption performance (including maximum sorption capacity and equilibrium time as criteria).

\subsubsection{Metal desorption and sorbent recycling}

Uranium sorption properties of PPA-PGMA/ $\mathrm{Fe}_{3} \mathrm{O}_{4}$ have been compared for six successive sorption/desorption cycles, using $0.25 \mathrm{M} \mathrm{NaHCO}_{3}$ solutions as the eluent. The bicarbonate solutions were used to prevent the damaging of $\mathrm{Fe}_{3} \mathrm{O}_{4}$ resulted from using the acidic solutions. The ability of carbonate to form complexes with uranyl species (such as $\mathrm{UO}_{2}\left(\mathrm{CO}_{3}\right)_{2}^{2-}, \mathrm{UO}_{2}\left(\mathrm{CO}_{3}\right)_{3}^{4-}$, etc.) may explain the quantitative elution of uranyl from loaded PPA-PGMA/ $\mathrm{Fe}_{3} \mathrm{O}_{4}$ nanocomposite (Imam et al., 2018; Kabay et al., 1998; Stopa and Yamaura, 2010). Sodium carbonate or ammonium carbonate solutions were successfully tested for uranyl desorption from a series of resins including Purolite S940, Lewatit OC 1060 while these eluents were much less efficient for metal desorption from Actinide - CU (silica-based resin bisphosphonate groups) (Kabay et al., 1998). In the case of magnetic chitosan particles loaded with uranyl ions, sodium carbonate solution was preferred against calcium oxalate for metal elution (Stopa and Yamaura, 2010). For chitosan functionalized with aminophosphonate groups the desorption of uranium was also efficiently processed using sodium bicarbonate solutions (Imam et al., 2018). Table 4 shows that the sorbent maintains a good stability in sorption performance, which is only reduced by $5 \%$ at the sixth cycle. The desorption also slightly decreases with material recycling; however, the decrease in desorption yield does not exceed $3 \%$ at the last cycle. These results confirm the high stability in the sorption and desorption performances of magnetic core-shell nanocomposite.

\subsection{Application to real effluents - metal recovery from pregnant liquor solution}

\subsubsection{Leachate preparation and pre-treatment - composition}

Table S6 reports the composition of the ore (major elements); uranium content in the ore reaches up to $1193.7 \mathrm{~g} \mathrm{ton}^{-1}$. Major compounds are associated to the mineralogical core (aluminosilicate of calcium, sodium, potassium and magnesium for about $87 \%$ ) and iron oxide (about 5.12\%). As expected the sulfuric acidic leaching of the ore produces an acid solution (PLS, pregnant liquor solution) containing high concentrations of $\mathrm{Si}$ (i.e., $83.24 \mathrm{~g} \mathrm{Si} \mathrm{L}^{-1}$ ), $\mathrm{Al}$ (i.e., $39.29 \mathrm{~g} \mathrm{Al} \mathrm{L}^{-1}$ ), Fe (i.e., $83.24 \mathrm{~g} \mathrm{Fe} \mathrm{L}^{-1}$ ) and $\mathrm{Ti}$ (i.e., $6.74 \mathrm{~g} \mathrm{Ti}$ $\left.\mathrm{L}^{-1}\right)$, in addition to alkaline and alkali-earth metals. The concentration of uranyl is about $0.976 \mathrm{~g} \mathrm{~L}^{-1}$. The mass balance on the leaching process shows that leaching efficiency is close to $81.8 \%$. In order to adjust the $\mathrm{pH}$ to the optimum conditions for $\mathrm{U}(\mathrm{VI})$ recovery, but also for decreasing the residual amount of major competitor elements, a pre-treatment of precipitation was applied through the control of the $\mathrm{pH}$ of the solution at $\mathrm{pH} 4$ (and subsequent filtration). As expected, the treatment precipitates between 20 and $80 \%$ of major elements; however, their residual concentrations in PPLS remain relatively high (mainly Si(IV), $\mathrm{Al}(\mathrm{III})$ ) K(I), K(I), Ca(II) and $\mathrm{Na}(\mathrm{I})$ ). Iron, which may be a strong competitor, reaches a concentration of the same order than $\mathrm{U}(\mathrm{VI})$ (i.e., $0.78 \mathrm{~g} \mathrm{Fe}^{-1}$ and $0.885 \mathrm{~g} \mathrm{U} \mathrm{L}^{-1}$, respectively). The loss of uranium at the precipitation step is below $10 \%$.

\subsubsection{Metal recovery by sorption on PPA-PGMA/Fe ${ }_{3} \mathrm{O}_{4}$}

Experimental conditions selected for sorption tests correspond to an excess of metal ions compared with the amount of sorbent used. The removal efficiency is not considered a relevant parameter for the evaluation of treatment performance. Data are exploited in terms of sorption capacities $\left(\mathrm{q}_{\mathrm{eq}}, \mathrm{mmol} \mathrm{g}^{-1}\right)$, distribution ratio (D, $\left.\mathrm{mL} \mathrm{mg}^{-1}\right)$ and selectivity coefficient $\left(\mathrm{SC}_{\text {metal } / \mathrm{U}}=\mathrm{D}_{\text {metal }} / \mathrm{D}_{\mathrm{U}}\right)$ (Fig. 4 ). The sorption capacity for $\mathrm{U}(\mathrm{VI})$ reaches $185.7 \mathrm{mg} \mathrm{U} \mathrm{g}^{-1}$ (i.e., $0.78 \mathrm{mmol} \mathrm{U} \mathrm{g}^{-1}$ ); this is much lower than the saturation capacity observed on synthetic solutions (i.e., $262.4 \mathrm{mg} \mathrm{U} \mathrm{g}^{-1}$, or $1.1 \mathrm{mmol} \mathrm{U}$

Table 4

Metal desorption and sorbent recycling.

\begin{tabular}{|c|c|c|c|c|}
\hline \multirow[t]{2}{*}{ Cycle \# } & \multicolumn{2}{|l|}{ Sorption step } & \multicolumn{2}{|l|}{ Desorption step } \\
\hline & Sorption efficiency (\%) & Sorption capacity (mg U g-1) & Desorption efficiency (\%) & Eluate conc. (mg U L-1) \\
\hline 1 & 100.0 & 262.4 & 99.1 & 520.1 \\
\hline 2 & 98.6 & 258.7 & 98.7 & 518.1 \\
\hline 3 & 97.5 & 255.9 & 97.7 & 513.0 \\
\hline 4 & 96.7 & 253.7 & 97.2 & 510.0 \\
\hline 5 & 95.7 & 251.2 & 96.5 & 506.6 \\
\hline 6 & 95.4 & 250.3 & 96.4 & 505.8 \\
\hline
\end{tabular}

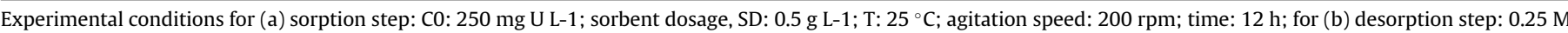
$\mathrm{NaHCO} 3$ solution; sorbent dosage, SD: $2 \mathrm{~g} \mathrm{~L}-1$; T: $25^{\circ} \mathrm{C}$; agitation speed: $200 \mathrm{rpm}$; time: $90 \mathrm{~min}$ ). 

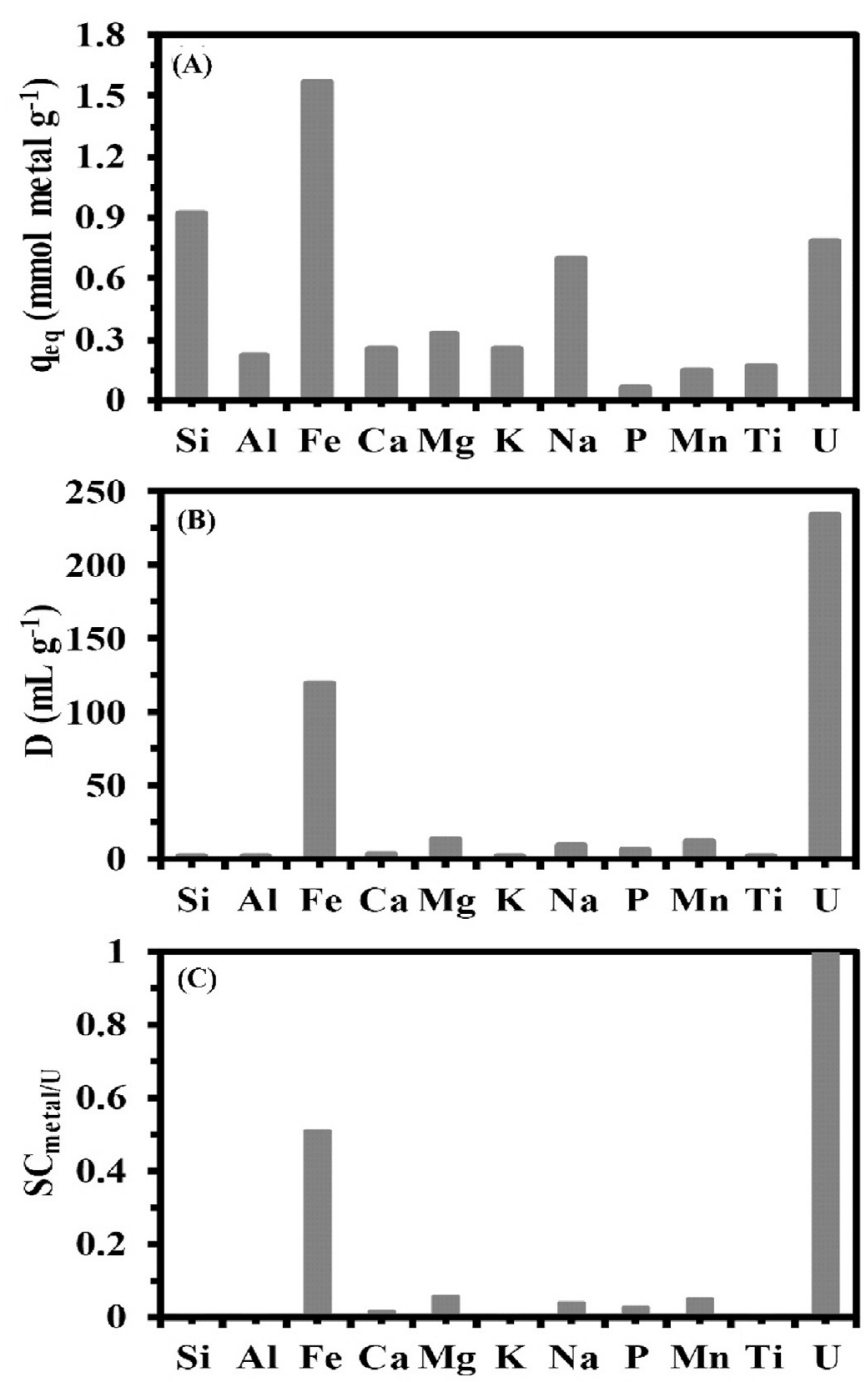

Fig. 4. Metal recovery from ore leachate (precipitated pregnant liquor solution, PPLS) - Sorption capacities (a), distribution ratios (b) and selectivity coefficients $\mathrm{SC}_{\text {metal/u }}$ (c) (pH 4; SD: $0.5 \mathrm{~g} \mathrm{~L}^{-1}$; T: $25 \pm 1{ }^{\circ} \mathrm{C}$; time: $3 \mathrm{~h}$; agitation speed: $200 \mathrm{rpm}$ ).

$\mathrm{g}^{-1}$ ) (Fig. 4a). This means that the presence of huge concentrations of co-ions reduces by $29 \%$ the maximum sorption; taking into account the large excess of the co-existing ions, the sorbent shows a marked affinity for $\mathrm{U}(\mathrm{VI})$. Some of the metal ions present in the solution are competing with uranyl for binding on the specific reactive groups of the sorbent. However, the total sorption capacity reaches $5.4 \mathrm{mmol}$ metal $\mathrm{g}^{-1}$; this is much higher than the maximum sorption capacity reached for $\mathrm{U}(\mathrm{VI})$ in mono-component synthetic solutions: other metal ions bind on the specific reactive groups through different stoichiometric ratios and/or different functional groups (such as non-substituted amine groups). The only metals that are significantly bound on PPA-PGMA/ $\mathrm{Fe}_{3} \mathrm{O}_{4}$ are $\mathrm{Si}(\mathrm{IV})$ (0.93 $\left.\mathrm{mmol} \mathrm{Si} \mathrm{g}^{-1}\right)$, Fe (1.57 $\left.\mathrm{mmol} \mathrm{Fe}^{-1}\right)$, and $\mathrm{Na}(\mathrm{I})(0.70 \mathrm{mmol} \mathrm{Na}$ $\left.\mathrm{g}^{-1}\right)$. Obviously, the sorption capacities are strongly influenced by the effective concentrations of the metals in PPLS; for this reason, the determination of the distribution ratio D highlights more efficiently the affinity of the sorbent for target metals (Fig. 4b). Hence, Fe and $\mathrm{U}(\mathrm{VI})$ have much higher D values (i.e., 119 and $234 \mathrm{~mL} \mathrm{~g}^{-1}$ ) than other co-ions (systematically lower than $13 \mathrm{~mL} \mathrm{~g}^{-1}$ ); the coefficient $D$ is very close to the enrichment factor (ratio of sorption capacity at equilibrium over initial concentration of the metal in PPLS). PPA-PGMA/ $\mathrm{Fe}_{3} \mathrm{O}_{4}$ tends to preferentially enrich $\mathrm{Fe}$ and $\mathrm{U}(\mathrm{VI})$.
The effective preference of PPA-PGMA/ $/ \mathrm{Fe}_{3} \mathrm{O}_{4}$ for $\mathrm{U}(\mathrm{VI})$ is confirmed by the analysis of selectivity coefficients $\left(\mathrm{SC}_{\text {metal }} \mathrm{U}\right.$, Fig. $\left.4 \mathrm{c}\right)$. The coefficients are systematically below 0.06 , except for $\mathrm{Fe}$ (i.e., $\mathrm{SC}_{\mathrm{Fe}}$ $\mathrm{U}=0.51$ ). The sorbent selectively remove $\mathrm{U}(\mathrm{VI})$ and Fe from complex acidic solutions.

\section{Conclusions}

The ball milling of magnetite particles with aminophosphonicfunctionalized poly(glycidyl methacrylate, PGMA) polymer particles allows preparing micro-sized particles constituted of magnetic nanoparticles (PPA-PGMA/ $\mathrm{Fe}_{3} \mathrm{O}_{4}$ ) having a high affinity for uranyl in solution. The high-energy process allows intimate association of the organic and inorganic compounds, with high stability in water and readily recovery while exposed to magnetic field (saturation magnetization: $18.2 \mathrm{emu} \mathrm{g}^{-1}$ ). The fraction of magnetite core in the sorbent is in the range $33-38 \%$. The Different steps in the functionalization of PGMA are identified by FTIR and XPS analyses. This is confirmed by the elemental analysis that shows the presence of about $1.58 \mathrm{mmol} \mathrm{P} \mathrm{g}^{-1}$ in the functionalized polymer (around $1.02 \mathrm{mmol} \mathrm{P} \mathrm{g}^{-1}$ in the magnetic sorbent) and the $6.77 \mathrm{mmol} \mathrm{N} \mathrm{g}^{-1}$ in the polymer compartment ( $3.32 \mathrm{mmol} \mathrm{N} \mathrm{g}^{-1}$ in the composite).

Uranyl sorption is enhanced at initial $\mathrm{pH}$ close to 4 (equilibrium $\mathrm{pH}$ being close to 3). This is consistent with the $\mathrm{pH}_{\mathrm{PZC}}$ (around 3) and the predominance of mononuclear free uranyl species. The nano/micro size of sorbent particles makes the sorption of uranyl a fast process: the equilibrium is reached within $2 \mathrm{~h}$ of contact under selected experimental conditions. The kinetic profiles are successfully fitted by the pseudo-second order rate equation; the resistance to intraparticle diffusion (simulated by the Crank equation) gives a good approximation of the concentration decay curve within $15 \mathrm{~min}$ ). The Langmuir equation successfully describes the sorption isotherm at $\mathrm{pH}_{0} 4$ and the maximum sorption capacity reaches around $270 \mathrm{mg} \mathrm{U} \mathrm{g}^{-1}$. The sorption capacity decreases with increasing temperature: the sorption process is exothermic. The sorbent shows a remarkable stability in terms of uranyl recovery for six successive cycles of sorption and desorption (using $0.25 \mathrm{M}$ $\mathrm{NaHCO}_{3}$ solution for metal elution). The sorbent is successfully applied for $U$ recovery from precipitated pregnant liquor solution (acidic leaching of uranium ores). The presence of huge concentrations of Fe and $\mathrm{Si}$ (despite a precipitation pre-treatment) reduces the sorption capacity of uranium. However, the sorption capacity reaches about $0.8 \mathrm{mmol} \mathrm{U} \mathrm{g}^{-1}$ (i.e., $190 \mathrm{mg} \mathrm{U} \mathrm{g}^{-1}$ ). In addition, the distribution ratio reaches values as high as $235 \mathrm{~mL} \mathrm{~g}^{-1}$; the sorbent has a remarkable selectivity against other metal ions; except for $\mathrm{Fe}$ (despite its preference for $\mathrm{U}(\mathrm{VI})$ against $\mathrm{Fe}$ ).

The microns-sized magnetic functionalized sorbent combines fast kinetics, high sorption capacities, high potential for regeneration and relatively high selectivity for $U(V I)$ against most of the metal ions present in acidic leaching liquors. This is a promising material for $\mathrm{U}(\mathrm{VI})$ recovery from complex solutions.

\section{Novelty statement}

A solid state method was developed to prepare core-shell nanocomposites using planetary ball milling technique. PGMA poly(glycidyl methacrylate) was first functionalized with amino and aminoalkyl phosphonic groups. Thereafter, the functionalized polymer was milled with preformed $\mathrm{Fe}_{3} \mathrm{O}_{4}$ nanoparticles to form PPA-PGMA/ $\mathrm{Fe}_{3} \mathrm{O}_{4}$ core-shell sorbent. This original method allows optimizing the synthesis of each compound independently. This paper also presents a new pathway for the epoxy ring opening (with appropriate characterization). The proposed epoxy ring opening reaction is opposite to previously published work. In addition, this work not only investigate synthetic solutions but a 
practical application is investigated. The sorbent reveals very selectivity for uranium from the leachate liquor (produced from local Egyptian ores) in the presence of high concentrations of cometal ions.

\section{Declaration of competing interest}

The authors declare that they have no known competing financial interests or personal relationships that could have appeared to influence the work reported in this paper.

\section{CRediT authorship contribution statement}

Ahmed A. Galhoum: Conceptualization, Supervision, Writing review \& editing. Wael H. Eisa: Conceptualization, Methodology, Investigation, Writing - review \& editing. Ibrahim El-Tantawy ElSayed: Formal analysis, Data curation, Writing - review \& editing. Ahmad A. Tolba: Conceptualization, Methodology, Data curation, Writing - original draft. Zeinab M. Shalaby: Conceptualization, Methodology, Investigation, Validation, Writing - original draft. Said I. Mohamady: Methodology, Validation, Investigation, Writing - original draft. Sally S. Muhammad: Conceptualization, Methodology, Investigation, Writing - original draft. Shimaa S. Hussien: Methodology, Investigation, Visualization, Validation. Takaya Akashi: Visualization, Resources, Funding acquisition. Eric Guibal: Software, Formal analysis, Data curation, Writing - review \& editing.

\section{Acknowledgements}

The Matsumae International Foundation, Japan (MIF-2016), Nuclear Materials Authority (Egypt), Hosei International Foundation, Japan (HIF-2017) and Staff members at Hosei University (Japan) are acknowledged for the technical and financial support. Institute Français d'Egypte (French Government) and Science and Technology Development Fund (Egyptian Government) are also acknowledged for supporting the collaboration between NMA, University of Menoufia and IMT-Mines Ales. Authors also thank Dr. Mai S. Maiz, (Faculty of Science, Menoufia University) for her technical support. Special dedication to the memory of Prof. Dr. Ahmed Donia.

\section{Appendix A. Supplementary data}

Supplementary data to this article can be found online at https://doi.org/10.1016/j.envpol.2020.114797.

\section{References}

Amphlett, J.T.M., Ogden, M.D., Foster, R.I., Syna, N., Soldenhoff, K.H., Sharrad, C.A., 2018a. The effect of contaminants on the application of polyamine functionalised ion exchange resins for uranium extraction from sulfate based mining process waters. Chem. Eng. J. 354, 633-640.

Amphlett, J.T.M., Sharrad, C.A., Foster, R.I., Ogden, M.D., 2018b. Ethylenediaminefuntionalized ion exchange resin for uranium recovery from acidic mixed sulphate-chloride media: initial column loading studies. J. S. Afr. Inst. Min. Metall 118, 1251-1257.

Ang, K.L., Li, D., Nikoloski, A.N., 2018. The effectiveness of ion exchange resins in separating uranium and thorium from rare earth elements in acidic aqueous sulfate media. Part 2. Chelating resins. Miner. Eng. 123, 8-15.

Awual, M.R., 2019. Novel ligand functionalized composite material for efficient copper(II) capturing from wastewater sample. Compos. B Eng. 172, 387-396.

Biswas, S., Rupawate, V.H., Hareendran, K.N., Roy, S.B., Chakravartty, J.K., 2015. Novel precipitation technique for uranium recovery from carbonate leach solutions. J. Radioanal. Nucl. Chem. 304, 1345-1351.

Burns, A.D., Abbasi, P., Dreisinger, D.B., 2016. Uranous sulfate precipitation as a novel hydrometallurgical process for uranium purification. Hydrometallurgy 163, 49-54.

Cao, Q., Liu, Y., Kong, X., Zhou, L., Guo, H., 2013. Synthesis of phosphorus-modified poly(styrene-co-divinylbenzene) chelating resin and its adsorption properties of uranium(VI). J. Radioanal. Nucl. Chem. 298, 1137-1147.

Chini, M., Crotti, P., Flippin, L.A., Macchia, F. 1990. Regiochemical control of the ringopening of 1,2-epoxides by means of chelating processes. Synthesis and reactions of the cis- and trans-oxides derived from 4-(benzyloxy)cyclohexene. J. Org. Chem. 55, 4265-4272.

Crawford, S.E., Lofts, S., Liber, K., 2017. The role of sediment properties and solution $\mathrm{pH}$ in the adsorption of uranium(VI) to freshwater sediments. Environ. Pollut. $220,873-881$.

Das, S., Pandey, A.K., Athawale, A.A., Manchanda, V.K., 2009. Exchanges of uranium(VI) species in amidoxime-functionalized sorbents. J. Phys. Chem. B 113 6328-6335.

Davies, W., Gray, W., 1964. A rapid and specific titrimetric method for the precise determination of uranium using iron(II) sulphate as reductant. Talanta 11, 1203-1211.

Dlamini, T.C., Tshivhase, V.M., Maleka, P., Penabei, S., Mashaba, M., 2019. The effect of uranium speciation on the removal of gross alpha activity from acid mine drainage using anion exchange resin. J. Radioanal. Nucl. Chem. 319, 357-363.

Durán Pachón, L., Gamez, P., van Brussel, J.J.M., Reedijk, J., 2003. Zinc-catalyzed aminolysis of epoxides. Tetrahedron Lett. 44, 6025-6027.

Duval, C.E., Hardy, W.A., Pellizzeri, S., DeVol, T.A., Husson, S.M., 2019. Phosphonic acid and alkyl phosphate-derivatized resins for the simultaneous concentration and detection of uranium in environmental waters. React. Funct. Polym. 137 133-139.

Eisa, W.H., Shabaka, A.A., 2013. Ag seeds mediated growth of Au nanoparticles within PVA matrix: an eco-friendly catalyst for degradation of 4-nitrophenol React. Funct. Polym. 73, 1510-1516.

El-Magied, M.O.A., Dhmees, A.S., Abd El-Hamid, A.A.M., Eldesouky, E.M., 2018. Uranium extraction by sulfonated mesoporous silica derived from blast furnace slag. J. Nucl. Mater. 509, 295-304.

Elsalamouny, A.R., Desouky, O.A., Mohamed, S.A., Galhoum, A.A., Guibal, E., 2017. Uranium and neodymium biosorption using novel chelating polysaccharide. Int. J. Biol. Macromol. 104, 963-968.

Elwakeel, K.Z., Atia, A.A., Guibal, E., 2014. Fast removal of uranium from aqueous solutions using tetraethylenepentamine modified magnetic chitosan resin. Bioresour. Technol. 160, 107-114.

Galhoum, A.A., Elshehy, E.A., Tolan, D.A., El-Nahas, A.M., Taketsugu, T., Nishikiori, K., Akashi, T., Morshedy, A.S., Guibal, E., 2019. Synthesis of polyaminophosphonic acid-functionalized poly(glycidyl methacrylate) for the efficient sorption of La(III) and Y(III). Chem. Eng. J. 375, 121932.

Gladysz-Plaska, A., Grabias, E., Majdan, M., 2018. Simultaneous adsorption of uranium(VI) and phosphate on red clay. Prog. Nucl. Energy 104, 150-159.

Guibal, E., Lorenzelli, R., Vincent, T., Lecloirec, P., 1995. Application of silica-gel to metal-ion sorption - static and dynamic removal of uranyl ions. Environ. Technol. 16, 101-114.

Han, Q. Setchi, R., Evans, S.L., 2016. Synthesis and characterisation of advanced ballmilled $\mathrm{Al}-\mathrm{Al}_{2} \mathrm{O}_{3}$ nanocomposites for selective laser melting. Powder Technol 297, 183-192.

Hasanpour, A., Niyaifar, M., Mohammadpour, H., Amighian, J., 2012. A novel nonthermal process of $\mathrm{TiO}_{2}$-shell coating on $\mathrm{Fe}_{3} \mathrm{O}_{4}$-core nanoparticles. J. Phys. Chem. Solid. 73, 1066-1070.

Huang, X., Dong, J., Wang, L., Feng, Z, Xue, O, Meng, X, 2017. Selective recovery of rare earth elements from ion-adsorption rare earth element ores by stepwise extraction with HEH(EHP) and HDEHP. Green Chem. 19, 1345-1352.

Imam, E.A., El-Tantawy El-Sayed, I., Mahfouz, M.G., Tolba, A.A., Akashi, T. Galhoum, A.A., Guibal, E., 2018. Synthesis of $\alpha$-aminophosphonate functionalized chitosan sorbents: effect of methyl vs phenyl group on uranium sorption. Chem. Eng. J. 352, 1022-1034.

James, D. Venkateswaran, G., Rao, T.P. 2009. Removal of uranium from mining industry feed simulant solutions using trapped amidoxime functionality within a mesoporous imprinted polymer material. Microporous Mesoporous Mater $119,165-170$.

Jiang, Z., Tijing, L.D., Amarjargal, A., Park, C.H., An, K.J., Shon, H.K., Kim, C.S. 2015. Removal of oil from water using magnetic bicomponent composite nanofibers fabricated by electrospinning. Compos. B Eng. 77, 311-318.

Kabay, N., Demircioglu, M., Yayli, S., Gunay, E., Yuksel, M., Saglam, M. Streat, M., 1998. Recovery of uranium from phosphoric acid solutions using chelating ionexchange resins. Ind. Eng. Chem. Res. 37, 1983-1990.

Kedari, C.S., Pandit, S.S., Gandhi, P.M., 2013. Separation by competitive transport of uranium(VI) and thorium(IV) nitrates across supported renewable liquid membrane containing trioctylphosphine oxide as metal carrier. J. Membr. Sci. 430, 188-195.

Kharissova, O.V., Dias, H.V.R., Kharisov, B.I., 2015. Magnetic adsorbents based on micro- and nano-structured materials. RSC Adv. 5, 6695-6719.

Kong, H., Song, J., Jang, J., 2010. One-step fabrication of magnetic gamma- $\mathrm{Fe}_{2} \mathrm{O}_{3} /$ polyrhodanine nanoparticles using in situ chemical oxidation polymerization and their antibacterial properties. Chem. Commun. 46, 6735-6737.

Kong, L., Zhang, H., Ji, W., Shih, K., Su, M., Diao, Z., Xu, R., Hou, L., Song, G., Chen, D., 2018. Recovery of phosphorus rich krill shell biowaste for uranium immobilization: a study of sorption behavior, surface reaction, and phase transformation. Environ. Pollut. 243, 630-636.

Liang, P.L., Yuan, L.Y., Deng, H., Wang, X.C., Wang, L., Li, Z.J., Luo, S.Z., Shi, W.Q., 2020. Photocatalytic reduction of uranium(VI) by magnetic ZnFe2O4 under visible light. Appl. Catal., B 267, 9.

Liu, C., Bai, R., Hong, L., 2006. Diethylenetriamine-grafted poly(glycidyl methacrylate) adsorbent for effective copper ion adsorption. J. Colloid Interface Sci. 303 
99-108.

Liu, S., Yang, Y. Liu, T., Wu, W., 2017. Recovery of uranium(VI) from aqueous solution by 2-picolylamine functionalized polystyrene-co-maleic anhydride) resin. J. Colloid Interface Sci. 497, 385-392.

Liu, Z., Liu, D., Cai, Z., Wang, Y., Zhou, L., 2018. Synthesis of new type dipropyl imide chelating resin and its potential for uranium(VI) adsorption. J. Radioanal. Nucl Chem. 318, 1219-1227.

Lopez-Ramon, M.V., Stoeckli, F., Moreno-Castilla, C., Carrasco-Marin, F., 1999. On the characterization of acidic and basic surface sites on carbons by various techniques. Carbon 37, 1215-1221.

Lu, W.S., Shen, Y.H., Xie, A.J., Zhang, W.Q., 2010. Green synthesis and characterization of superparamagnetic Fe304 nanoparticles. J. Magn. Magn Mater. 322 $1828-1833$.

Lu, X., Zhang, D., Tesfay Reda, A., Liu, C., Yang, Z., Guo, S., Xiao, S., Ouyang, Y., 2017. Synthesis of amidoxime-grafted activated carbon fibers for efficient recovery of uranium(VI) from aqueous solution. Ind. Eng. Chem. Res. 56, 11936-11947.

Mahfouz, M.G., Galhoum, A.A., Gomaa, N.A., Abdel-Rehem, S.S., Atia, A.A., Vincent, T., Guibal, E., 2015. Uranium extraction using magnetic nano-based particles of diethylenetriamine-functionalized chitosan: equilibrium and kinetic studies. Chem. Eng. J. 262, 198-209.

Marcus, Y., 1997. Ion Properties. Marcel Dekker, Inc., New York, NY.

Marczenko, Z., 1986. Separation and Spectrophotometric Determination of Elements, 2nd. Ed. Ellis Horwood, Chichester, UK.

Mathew, K.J., Buerger, S., Vogt, S., Mason, P., Morales-Arteaga, M.E., Narayanan, U.I. 2009. Uranium assay determination using Davies and Gray titration: an overview and implementation of GUM for uncertainty evaluation. J. Radioanal. Nucl. Chem. 282, 939-944.

Mazario, E., Stemper, J., Helal, A.S., Mayoral, A., Decorse, P., Losno, R., Lion, C., Ammar, S., Le Gall, T., Hemadi, M., 2019. New iron oxide nanoparticles catecholgrafted with bis(amidoxime)s for uranium(VI) depletion of aqueous solution. J. Nanosci. Nanotechnol. 19, 4911-4919.

Mincke, S., Asere, T.G., Verheye, I., Folens, K., Vanden Bussche, F., Lapeire, L., Verbeken, K., Van Der Voort, P., Tessema, D.A., Fufa, F., Du Laing, G., Stevens, C.V. 2019. Functionalized chitosan adsorbents allow recovery of palladium and platinum from acidic aqueous solutions. Green Chem. 21, 2295-2306.

Negm, S.H., Abd El-Hamid, A.A.M., Gado, M.A., El-Gendy, H.S., 2019. Selective uranium adsorption using modified acrylamide resins. J. Radioanal. Nucl. Chem. 319, 327-337.

Olivelli, M.S., Curutchet, G.A., Torres Sanchez, R.M., 2013. Uranium uptake by montmorillonite-biomass complexes. Ind. Eng. Chem. Res. 52, 2273-2279.

Ortaboy, S., Atun, G., 2014. Kinetics and equilibrium modeling of uranium(VI) sorption by bituminous shale from aqueous solution. Ann. Nucl. Energy 73, $345-354$.

Philippova, O., Barabanova, A., Molchanov, V., Khokhlov, A., 2011. Magnetic polymer beads: recent trends and developments in synthetic design and applications. Eur. Polym. J. 47, 542-559.

Rahmani-Sani, A., Hosseini-Bandegharaei, A., Hosseini, S.H., Kharghani, K., Zarei, H. Rastegar, A. 2015. Kinetic, equilibrium and thermodynamic studies on sorption of uranium and thorium from aqueous solutions by a selective impregnated resin containing carminic acid. J. Hazard Mater. 286, 152-163.

Ramos, V.M., Rodriguez, N.M., Diaz, M.F., Rodriguez, M.S., Heras, A., Agullo, E., 2003. $\mathrm{N}$-methylene phosphonic chitosan. Effect of preparation methods on its properties. Carbohydr. Polym. 52, 39-46.

Rao, T.P., Metilda, P., Gladis, J.M., 2006. Preconcentration techniques for uranium(VI) and thorium(IV) prior to analytical determination - an overview. Talanta 68, 1047-1064.

Ren, Y., Yang, R., Shao, L., Tang, H., Wang, S., Zhao, J., Zhong, J., Kong, C., 2016. The removal of aqueous uranium by SBA-15 modified with phosphoramide: combined experimental and DFT study. RSC Adv. 6, 68695-68704.
Rodas Ceballos, M., Gonzalez Serra, F., Manuel Estela, J., Cerda, V., Ferrer, L., 2019. 3D printed resin-coated device for uranium (VI) extraction. Talanta 196, 510-514.

Shapiro, L., 1975. Rapid analysis of silicate, carbonate, and phosphate rocks. In: Bulletin, - (Ed.), US Geol. Surv. Bull. 76 pIII, Report Number 1401, p. Pp. 88.

Solgy, M., Taghizadeh, M., Ghoddocynejad, D., 2015. Adsorption of uranium(VI) from sulphate solutions using Amberlite IRA-402 resin: equilibrium, kinetics and thermodynamics study. Ann. Nucl. Energy 75, 132-138.

Song, S., Wang, K., Zhang, Y., Wang, Y., Zhang, C., Wang, X., Zhang, R., Chen, J., Wen, T. Wang, X., 2019. Self-assembly of graphene oxide/PEDOT:PSS nanocomposite as a novel adsorbent for uranium immobilization from wastewater. Environ. Pollut. 250, 196-205.

Stoia, M., Istratie, R., Păcurariu, C., 2016. Investigation of magnetite nanoparticles stability in air by thermal analysis and FTIR spectroscopy. J. Therm. Anal. Calorim. 125, 1185-1198.

Stopa, L.C.B., Yamaura, M., 2010. Uranium removal by chitosan impregnated with magnetite nanoparticles: adsorption and desorption. Int. J. Nucl. Energy Sci. Technol. 5, 283-289.

Sun, X., Yang, L., Xing, H., Zhao, J., Li, X., Huang, Y., Liu, H., 2013. Synthesis of polyethylenimine-functionalized poly(glycidyl methacrylate) magnetic microspheres and their excellent $\mathrm{Cr}(\mathrm{VI})$ ion removal properties. Chem. Eng. J. 234, $338-345$.

Sureshkumar, M.K., Das, D., Mallia, M.B., Gupta, P.C., 2010. Adsorption of uranium from aqueous solution using chitosan-tripolyphosphate (CTPP) beads. J. Hazard Mater. 184, 65-72.

Wang, H., Ma, L., Cao, K., Geng, J., Liu, J., Song, Q., Yang, X., Li, S., 2012. Selective solidphase extraction of uranium by salicylideneimine-functionalized hydrothermal carbon. J. Hazard Mater. 229, 321-330.

Weber, W.J., Morris, J.C., 1963. Kinetics of adsorption on carbon from solutions. Journal of Sanitary Engineering Div. ASCE 89, 31-60.

Xiao, F., Cheng, J., Cao, W., Yang, C., Chen, J., Luo, Z., 2019. Removal of heavy metals from aqueous solution using chitosan-combined magnetic biochars. J. Colloid Interface Sci. 540, 579-584.

Xie, Y., Chen, C.L., Ren, X.M., Wang, X.X., Wang, H.Y., Wang, X.K., 2019. Emerging natural and tailored materials for uranium-contaminated water treatment and environmental remediation. Prog. Mater. Sci. 103, 180-234.

Yin, L., Wang, P., Wen, T., Yu, S., Wang, X., Hayat, T., Alsaedi, A., Wang, X., 2017. Synthesis of layered titanate nanowires at low temperature and their application in efficient removal of U(VI). Environ. Pollut. 226, 125-134.

Yin, X.J., Bai, J., Fan, F.L., Cheng, W.W., Tian, W., Wang, Y., Qin, Z., 2015. Amidoximed silica for uranium(VI) sorption from aqueous solution. J. Radioanal. Nucl. Chem. 303, 2135-2142.

Yu, B., Ye, G., Chen, J., Ma, S., 2019. Membrane-supported 1D MOF hollow superstructure array prepared by polydopamine-regulated contra-diffusion synthesis for uranium entrapment. Environ. Pollut. 253, 39-48.

Yuan, L.-Y., Liu, Y.-L., Shi, W.-Q., Lv, Y.-L., Lan, J.-H., Zhao, Y.-L., Chai, Z.-F., 2011. High performance of phosphonate-functionalized mesoporous silica for U(VI) sorption from aqueous solution. Dalton Trans. 40, 7446-7453.

Zayed, M.F., Eisa, W.H., Anis, B., 2015. Removal of methylene blue usingPhoenix dactylifera/PVA composite; an eco-friendly adsorbent. Desalination and Water Treatment 57, 18861-18867.

Zhang, C., Dodge, C.J., Malhotra, S.V., Francis, A.J., 2013. Bioreduction and precipitation of uranium in ionic liquid aqueous solution by Clostridium sp. Bioresour. Technol. 136, 752-756.

Zhang, Z., Dong, Z., Dai, Y., Xiao, S., Cao, X., Liu, Y., Guo, W., Luo, M., Le, Z., 2016. Amidoxime-functionalized hydrothermal carbon materials for uranium removal from aqueous solution. RSC Adv. 6, 102462-102471.

Zhu, Z.W., Pranolo, Y., Cheng, C.Y., 2016. Uranium recovery from strong acidic solutions by solvent extraction with Cyanex 923 and a modifier. Miner. Eng. 89, $77-83$. 